\title{
Regenerative Braking in Electric Vehicle Using Quadratic Gain Bidirectional Converter
}

\author{
Mukesh Kumar $\mathbb{D}^{1}{ }^{1}$ Kumar Abhishek Singh $\mathbb{D}^{1},{ }^{1}$ Kalpana Chaudhary ${ }^{\mathbb{D}},{ }^{1}$ R. K. Saket ${ }^{\mathbb{D}},{ }^{1}$ \\ and Baseem Khan $\mathbb{D i D}^{2}$ \\ ${ }^{1}$ Department of Electrical Engineering, Indian Institute of Technology (BHU), Varanasi, Uttar Pradesh, India \\ ${ }^{2}$ Department of Electrical and Computer Engineering, Hawassa University, Awasa, Ethiopia \\ Correspondence should be addressed to Baseem Khan; baseem.khan04@gmail.com
}

Received 30 September 2021; Revised 9 December 2021; Accepted 13 December 2021; Published 31 January 2022

Academic Editor: N. Prabaharan

Copyright (c) 2022 Mukesh Kumar et al. This is an open access article distributed under the Creative Commons Attribution License, which permits unrestricted use, distribution, and reproduction in any medium, provided the original work is properly cited.

\begin{abstract}
The manuscript proposes a quadratic gain bidirectional converter (QGBC). The proposed converter is operated in two different stages-step-up (motoring) and step-down (regenerative braking) - which can be employed in electric vehicle (EV) applications. The converter is operated in the continuous inductor current mode (CICM). For regenerative braking (RB) of permanent magnet brushless DC (PMBLDC) motor, the self-inductance of the motor is exploiting to step up the back electromagnetic force (EMF) of the motor to extract the energy even at low rotor speed. The design parameters of the converter are selected as battery voltage $V_{s}=48 \mathrm{~V}$, output voltage $V_{o}=200 \mathrm{~V}$, output power $P_{o}=1 \mathrm{~kW}$, and switching frequency $f_{s}=20 \mathrm{kHz}$. The design system is simulated using MATLAB/Simulink. Finally, a $1 \mathrm{~kW}$ prototype is developed for validation and performance analysis of the converter. The converter operates at maximum efficiency of $95 \%$ during step-up operation of the converter. A DSP microcontroller TMS320F28335 is used to control the switches of the converter in the experimental setup.
\end{abstract}

\section{Introduction}

The advancement of technology and standards of living continues to enhance. Nowadays, most of the works depend on electrical energy. Many commercial applications, such as uninterrupted power supply, electric vehicles (EVs), and microgrids. Batteries and bidirectional DC-DC converters (BDCs) have the main role for these systems. In recent years, the whole world moving towards the electric vehicle as fossil fuel are devastating and concern of environmental effect. In the vehicle, the motor drive and power electronic converter should be capable of bidirectional energy interference with the battery and motor drive system. A high gain $\mathrm{BDC}$ is proposed in $[1,2]$. The high gain BDCs are used in electric vehicles (EVs) as they convert low voltage to high voltage and recovery of energy during regenerative braking (RB) which will enhance the driving range of the vehicle. Figure 1 explicate the electrical system of an EV which consists of a battery, BDC, DC-AC converter, electrical machine, and transmission system. Many high gain converter topologies have been proposed that can be categorized in different ways: isolated and nonisolated circuits. The transformerbased and isolated topology [3-5], a transformer or coupled inductor, is used for high gain. The problem with coupledinductor or transformer has leakage inductance. To overcome the problem of leakage inductance, a snubber circuit is used. The nonisolated BDC topologies [6,7] are simple in design and controlling without galvanic isolation.

Due to the simple design and without galvanic isolation, the converter size, and low cost, the nonisolated BDC is most preferred. Due to circuit parasitic components, a high duty cycle, and voltage stress on switches, this converter has a restricted voltage gain. To get a high voltage gain, different topologies have been proposed a few years back [8] to reduce voltage stress. A coupled inductor is used, but due to the presence of leakage inductance which increases the voltage stress, additional clamping circuit is used to reduce the voltage stress. A multiport transformerless converter $[9,10]$ 


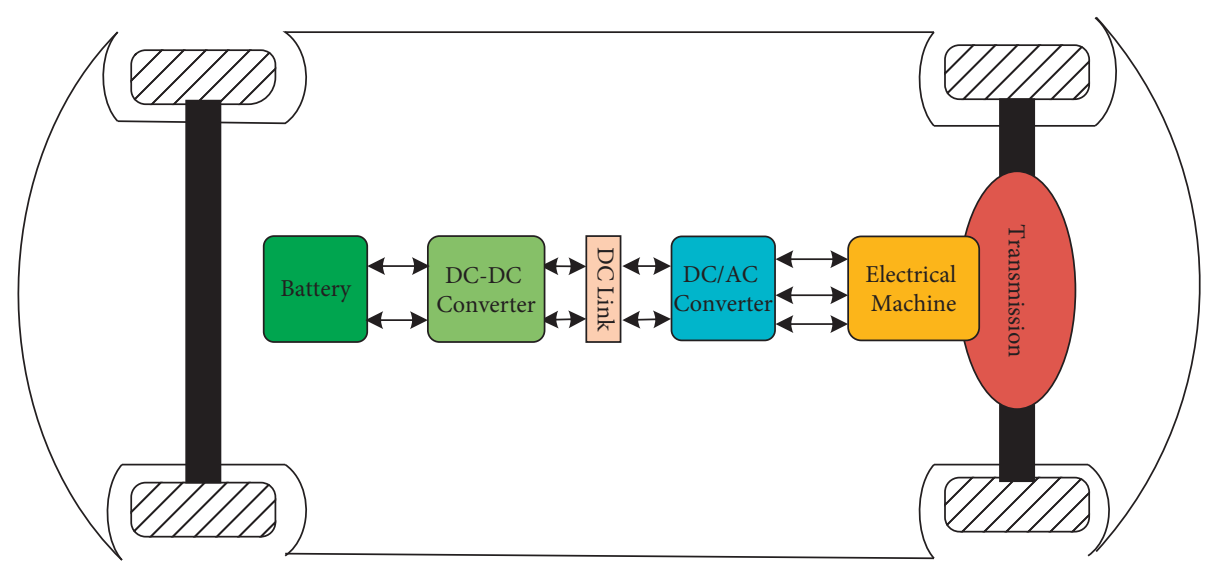

FIgUre 1: Electrical system of an EVs powertrain.

is for EV application. In this converter, only three switches are used for bidirectional buck-boost operation with dual input and dual output ports, but the voltage gain is same as the conventional boost converter. For the converter for relatively high voltage conversion ratio, there are several coupled-inductor bidirectional converters presented in [11, 12]. In an integrated coupled-inductor converter low ripple current, low voltage stress and soft switching can be achieved by employing phase-shift angle modulation. A dual-switch buck/ boost converter [13] has minimal power loss and excellent efficiency; however, the switch is under a high voltage stress. In $[14,15]$, a switched quasi-Z-source BDC is presented by alteration in the place of the main power switch in a conventional two-level quasi-Z-source BDC for improvement of conversion efficiency, but it requires more number of the power switch. To get higher voltage gain without wider duty cycle operation, a voltage multiplier circuit (VMC) [16] is proposed. The number of diodes required for $2 \mathrm{~N}-1$ combinations for $\mathrm{N}$ diode-capacitor $\mathrm{VMC}$ and $\mathrm{N}$ fold of voltage gain are described in details. A switched-capacitor interleaved $[17,18]$ bidirectional converter for wide voltage conversion ratio in EVs is presented in this work. In interleaved bidirectional converter number of power switches, components and size are large for high voltage conversion ratio.

There are different resonant converters used for wide voltage gain and higher efficiency $[19,20]$. In this fixed frequency, the phase-shift control technique is used, and soft switching is applied for minimum switching loss. There are different topologies of quadratic voltage gain converter proposed in [21, 22]. This quadratic converter has a ripple current on the low voltage side which affects the performance of the battery/supercapacitor. To reduce the ripple current on the low voltage side, a coupled inductor-based quadratic converter [23] is described. In the presence of leakage inductance of coupled inductor, the voltage stress on switches will increase and voltage gain is the same as the quadratic converter. To show the $\mathrm{RB}$, the reversal of power flow from load to source is established. For reversal of power flow, the controlling of the voltage source inverter (VSI) to the power is flowing from load to source. The method for RB of brushless DC motor-based EV is done in $[24,25]$. In this $\mathrm{RB}$, we boost the back electromagnetic force (EMF) of PMBLDC machine to DC bus voltage with the help of self-inductance of PMBLDC machine. Another technique for controlling VSI during RB is described in [26]. In this, a T-S sliding-mode approach control technique is used for $\mathrm{RB}$ in the electric vehicle. A bidirectional buck-boost converterbased permanent magnet DC machine drive system for RB in an $\mathrm{EV}$ is presented in [27].

In this paper, a quadratic gain bidirectional converter (QGBC) is connected to a load as shown in Figure 2. The load consists of a VSI fed PMBLDC motor, and the motor is coupled to a pulley and belt. The proposed converter has the following advantages: high voltage gain at a low duty cycle, fewer power switches, a simple construction, and easy control. Section 2 describes the topology and converter's operation, and Section 3 gives the details of converter design. The simulation and experimental results are described in Section 4 , and the conclusion of the work is given in Section 5.

\section{Topology and Operation of Converter}

The proposed QGBC with battery and load is illustrated in Figure 2. Here, $V_{s}$ is input voltage, $V_{c}$ is voltage across capacitor $C_{1}, V_{o}$ is output voltage, $I_{L 1}$ is inductor current of $L_{1}$, and $I_{L 2}$ is inductor current of $L_{2}$. In the proposed converter, it consists of four power switches $S_{1}, S_{2}, S_{3}$, and $S_{4}$ with antiparallel diode. The converter's operation in the step-up switches $S_{1}$ and $S_{2}$ is controlled, and converter's operation in the step-down switches $S_{3}$ and $S_{4}$ are controlled. The load on the converter consists of VSI fed PMBLDC Motor with a pulley and belt in the converter's step-up operation.

2.1. Step Up or Motoring Mode Operation. The converter's step-up operation is described in two different stages. In the step-up mode, energy is transferred from battery to load through controlled switches $S_{1}$ and $S_{2}$. The working waveform of converter's operation in the step-up mode is described in Figure 3.

Stage I $\left(t_{o}, t_{1}\right)$ : in this stage, the $S_{1}$ and $S_{2}$ switches are $\mathrm{ON}$ and $S_{3}$ and $S_{4}$ switches are OFF for the time interval of $D T_{s}$. The inductor $L_{1}$ current is increasing, and energy is transferred to inductor from battery. The converter's operation in this stage is shown in 


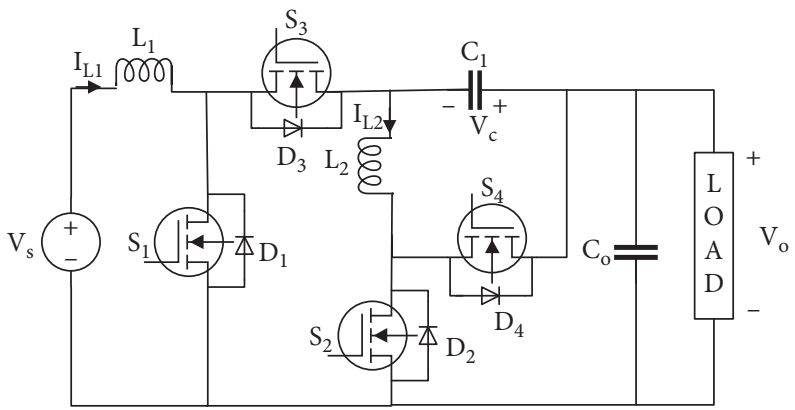

Figure 2: Proposed quadratic gain bidirectional DC-DC converter.

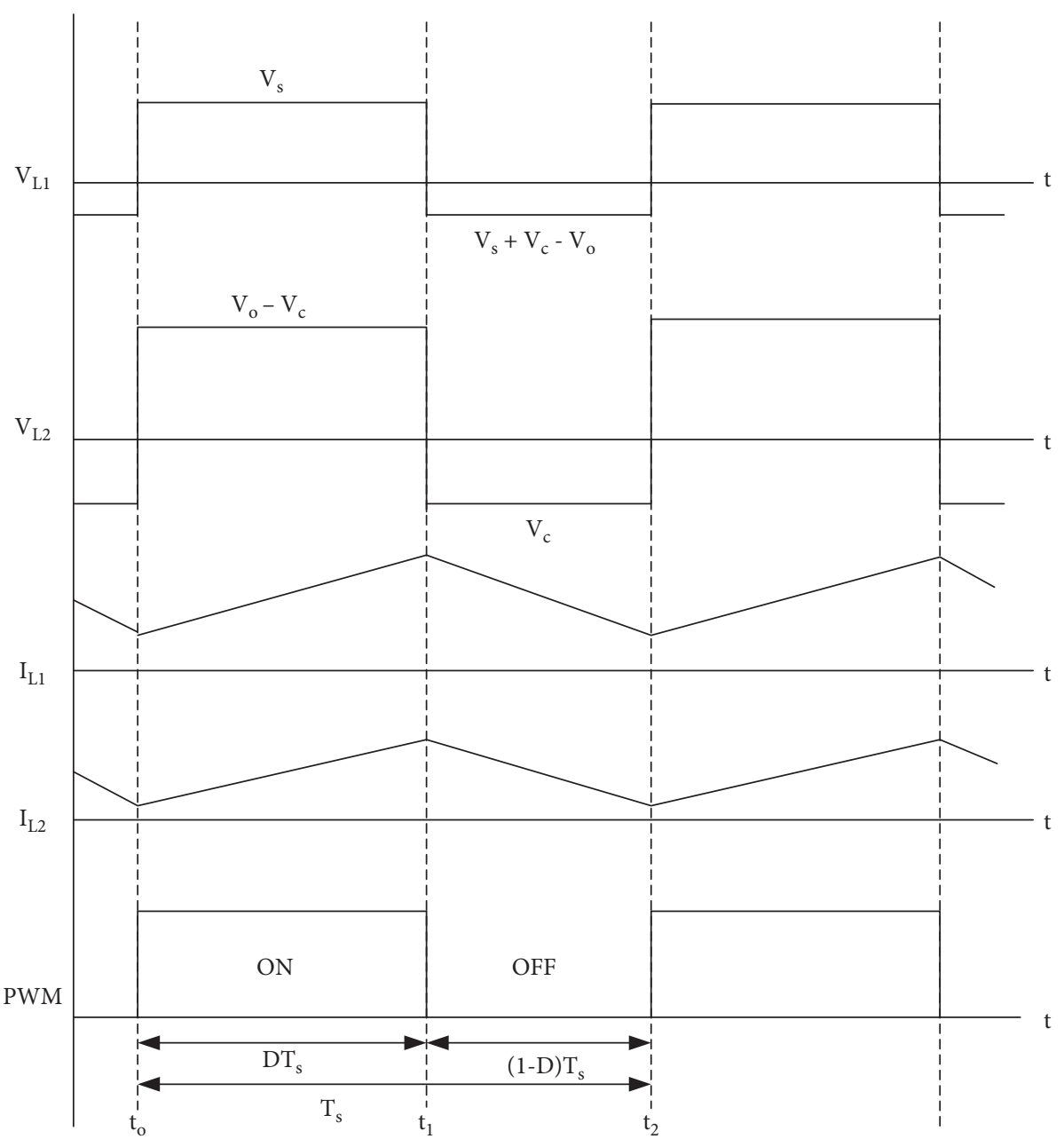

FIGURE 3: Working waveform of converter's operation in step-up.

Figure 4(a). Capacitor $C_{o}$ supplies energy to load, inductor $L_{2}$ current increases, and capacitor $C_{1}$ charges. Stage II $\left(t_{1}, t_{2}\right)$ : in this stage, all the switches $S_{1}, S_{2}, S_{3}$, and $S_{4}$ are OFF for time interval $(1-D) T_{s}$. The stored energy in inductor $L_{1}$ and inductor $L_{2}$ is transferred to load. During this interval, both inductors' current decreases. The converter's operation in this stage is shown in Figure 4(b). Upon application of Volt-sec balance principle on inductor $L_{1}$ and $L_{2}$, the following equation is obtained:

$$
\begin{gathered}
D V_{s}+(1-D)\left(V_{s}+V_{c}-V_{o}\right)=0, \\
D\left(V_{c}-V_{o}\right)+(1-D) V_{c}=0, \\
V_{o}=\frac{V_{s}}{(1-D)^{2}} .
\end{gathered}
$$




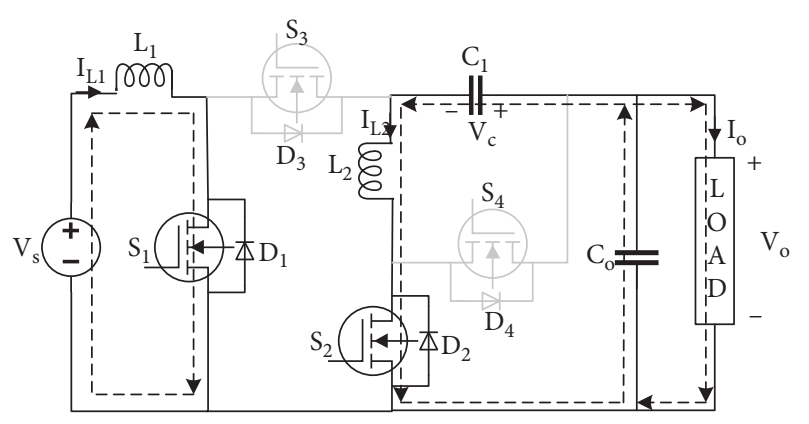

(a)

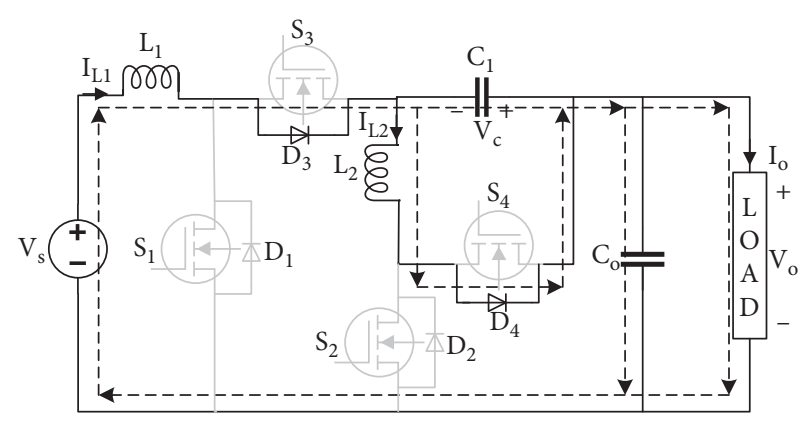

(b)

FIgURE 4: Current flowing path during step-up mode operation of the converter. (a) Stage I. (b) Stage II.

By eliminating $V_{c}$ from equations (1) and (2), the output voltage during step-up operation is obtained in equation (3) quadratic in nature. Voltage across capacitor $C_{1}$ is obtained as

$$
V_{c}=D V_{o}=\frac{D V_{s}}{(1-D)^{2}}
$$

\subsection{Step Down or Regenerative Braking Mode Operation.} The step-down mode operation of converter is described in two different stages. In RB operation of converter, the energy is transferred from load to battery by controlling switches $S_{3}$ and $S_{4}$. The working waveform of the converter during regenerative braking is described in Figure 5.

Stage I $\left(t_{o}, t_{1}\right)$ : in this stage, the switches $S_{3}$ and $S_{4}$ are ON and switches $S_{1}$ and $S_{2}$ are OFF during the time interval $D T_{s}$. During this interval, both inductors' current increases, and energy is transferred from higher voltage to lower voltage. The converter's operation in this stage is shown in Figure 6(a).

Stage II $\left(t_{1}, t_{2}\right)$ : in this stage, all switches $S_{1}, S_{2}, S_{3}$, and $S_{4}$ are OFF during the interval $(1-D) T_{s}$. During this interval, the stored energy in inductor $L_{1}$ is transferred to load and the energy stored in inductor $L_{2}$ is transferred to capacitor $C_{1}$. The converter's operation in this stage is shown in Figure 6(b).

$$
\begin{aligned}
& D\left(V_{o}-V_{c}-V_{s}\right)+(1-D)\left(-V_{s}\right)=0, \\
& -D V_{c}+(1-D)\left(V_{o}-V_{c}\right)=0, \\
& V_{s}=D^{2} V_{o} .
\end{aligned}
$$

By eliminating $V_{c}$ from equations (4) and (5), the output voltage of the converter during the step-down mode is obtained in equation (6) quadratic in nature.

2.3. Working of VSI during Regenerative Braking of PMBLDC Motor. In the RB (step-down), the energy has to flow from the PMBLDC machine to the battery. During RB, the PMBLDC machine acts as a generator, and kinetic energy stored in the vehicle can be transferred to the battery by reversal of current flow. Only by controlling the converter can it not siphon the mechanical energy from the PMBLDC machine, and the machine is needed to be operated in the II quadrant. Instead of direct rectification, a back EMF boosting technique is applied in this work during regenerative braking. The self inductances of the PMBLDC machine are charged by shorting all three phases together. All the switches on the high side are turned OFF, and switches on the low side are turn ON and OFF together. When all the switches are on the low side, the energy is stored in the self-inductance of the PMBLDC machine, and all switches are OFF; the stored energy in these inductances is transferred to the converter's output capacitor $\left(C_{o}\right)$. The equivalent circuit of two active phases of the VSI braking and switching PWM of VSI during regenerative phase is shown in Figures 7(a) and 7(b), respectively.

\section{Converter Design and Stability Analysis}

3.1. Converter Design Consideration. The converter design is done as per its step-up and step-down operations, and the converter operates in boundary condition mode for step-up. In the boundary condition mode, the minimum value of inductor $L_{2}$ is zero at the beginning of stage I. The working waveform of the converter in boundary condition is shown in Figure 8(a). In boundary condition operation, the current in inductor $L_{1}$ is continuous. The inductor's computation is dependent on the current ripple.

Let us consider the current in inductor $L_{2}$ is $i_{L 2}$; thus, the change in current is described as

$$
\frac{\mathrm{d} i_{L 2}}{\mathrm{~d} t}=\frac{V_{L 2}}{L_{2}}
$$

Assuming a linear variation and consider $i_{L 2_{m} \text { in }}=0$, the following equation is obtained:

$$
\frac{\Delta i_{L 2}}{\Delta t}=\frac{i_{L 2 \max }-i_{L 2 \min }}{\Delta t}=\frac{i_{L 2 \max }}{\Delta t}=\frac{V_{L 2}}{L_{2}} .
$$

When the switch $S_{2}$ is turned $\mathrm{ON}$, considering $\Delta t=D T_{s}$, $T_{s}=1 / f_{s}$, and $V_{L 2}=V_{o}-V_{c}$, the maximum current of inductor $L_{2}$ is given as

$$
i_{L 2 \max }=\frac{V_{0}-V_{c}}{L_{2} f_{s}} D .
$$




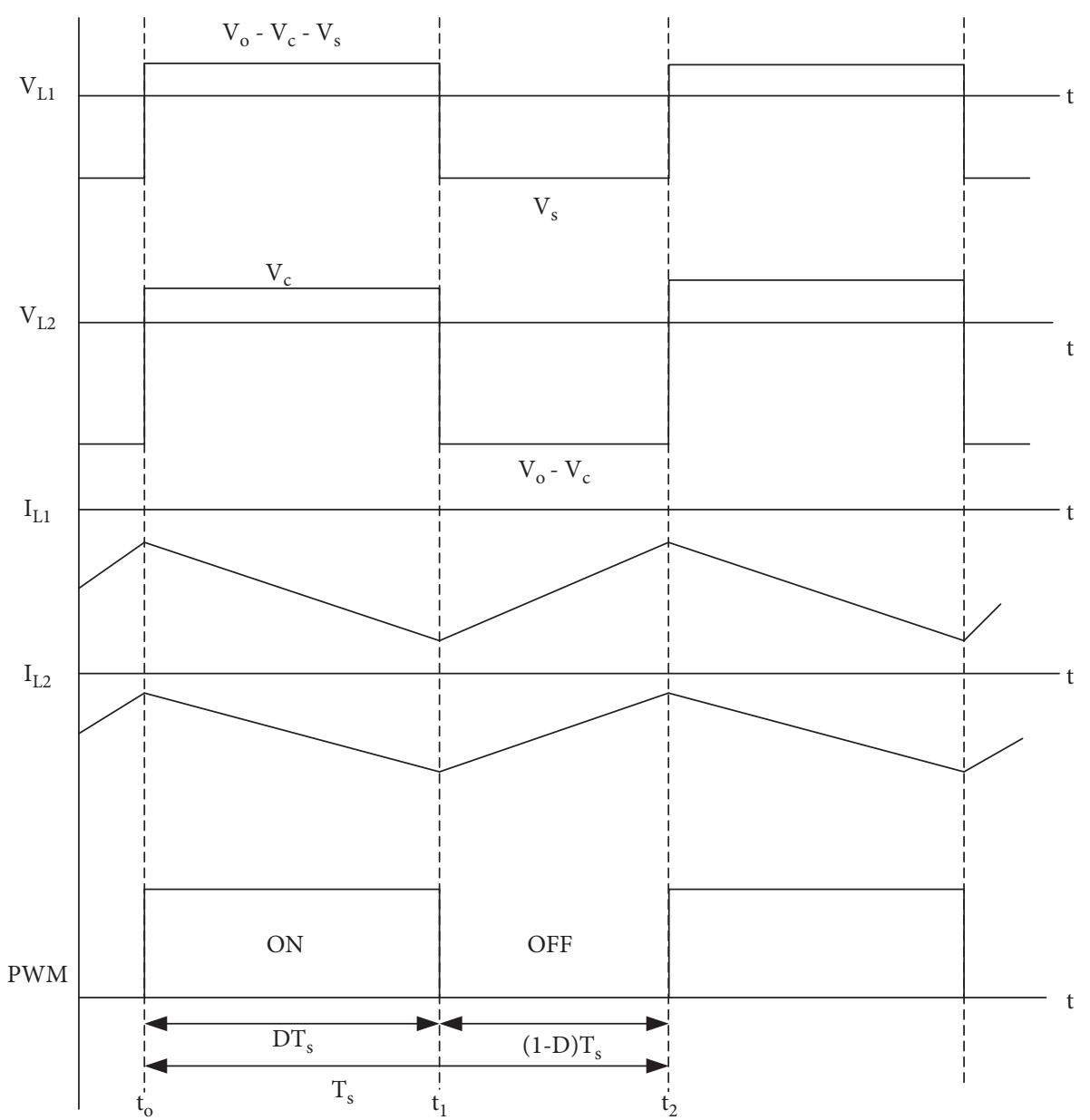

FIgURE 5: Working waveform of converter in step-down operation.

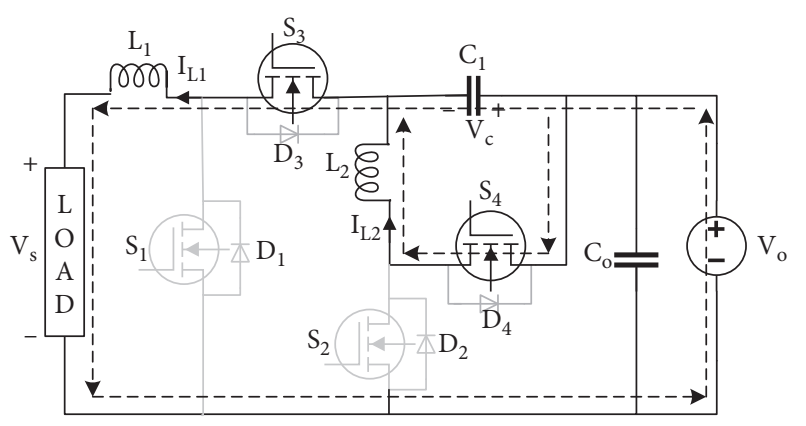

(a)

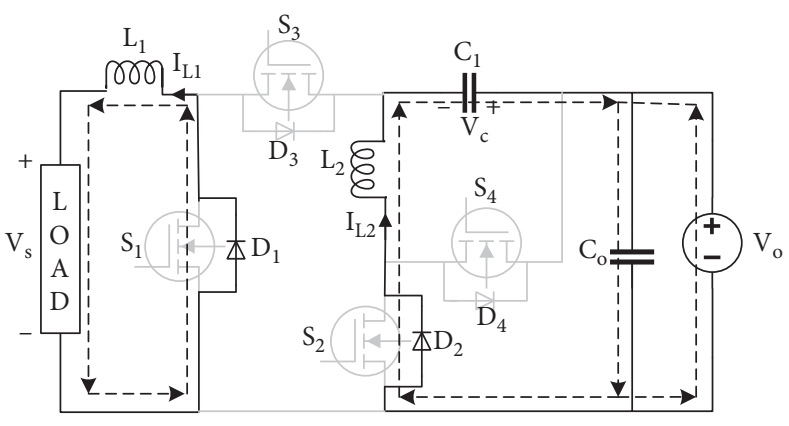

(b)

Figure 6: Current flowing path during step-down mode operation of the converter. (a) Step I. (b) Step II.

To avoid the boundary condition mode, it must satisfy these conditions:

$$
i_{L 2 \min } \geq 0 \Rightarrow I_{L 2 \min } \geq I_{L 2 \mathrm{avg}}-\frac{i_{L 2 \max }}{2} .
$$

Substituting equations (3), (4), and (11) into equation (10), the critical value of inductor $L_{2}$ is a function of duty cycle, $D$

$$
L_{2} \geq \frac{V_{o}}{2 I_{\text {L2avg }} f_{s}}(1-D) D .
$$

Assuming constant output voltage $V_{o}$ and switching frequency $f_{s}$, the value of duty cycle $(D)$ which gives maximum value of $L_{2}$. The value of $D$ is obtained by calculating first derivative of equation (12) with respect to $D$ and equals to zero, the $D$ is obtained as $1 / 2$. Therefore, the value of $L_{2}$ is given as 


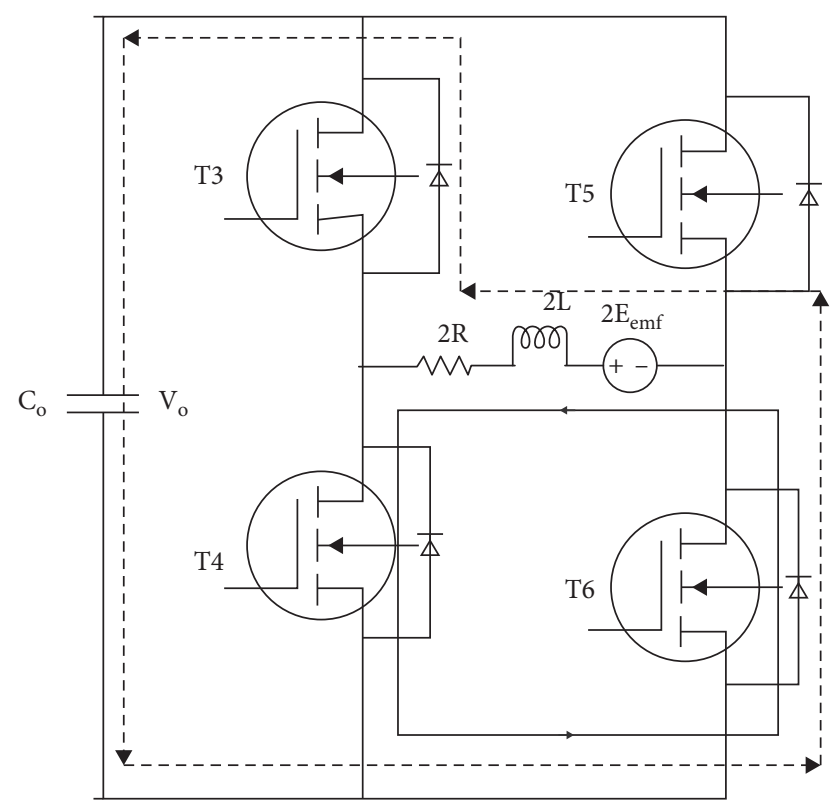

(a)

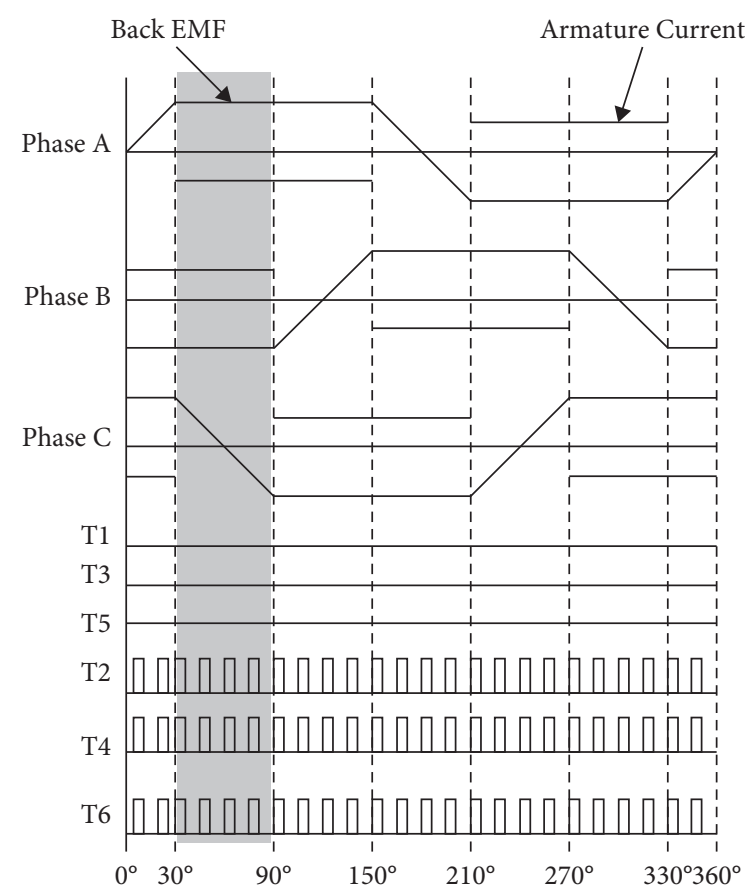

(b)

Figure 7: (a) Equivalent circuit consisting of two active phases of VSI during regenerative braking. (b) Switching signal of VSI during regenerative braking.

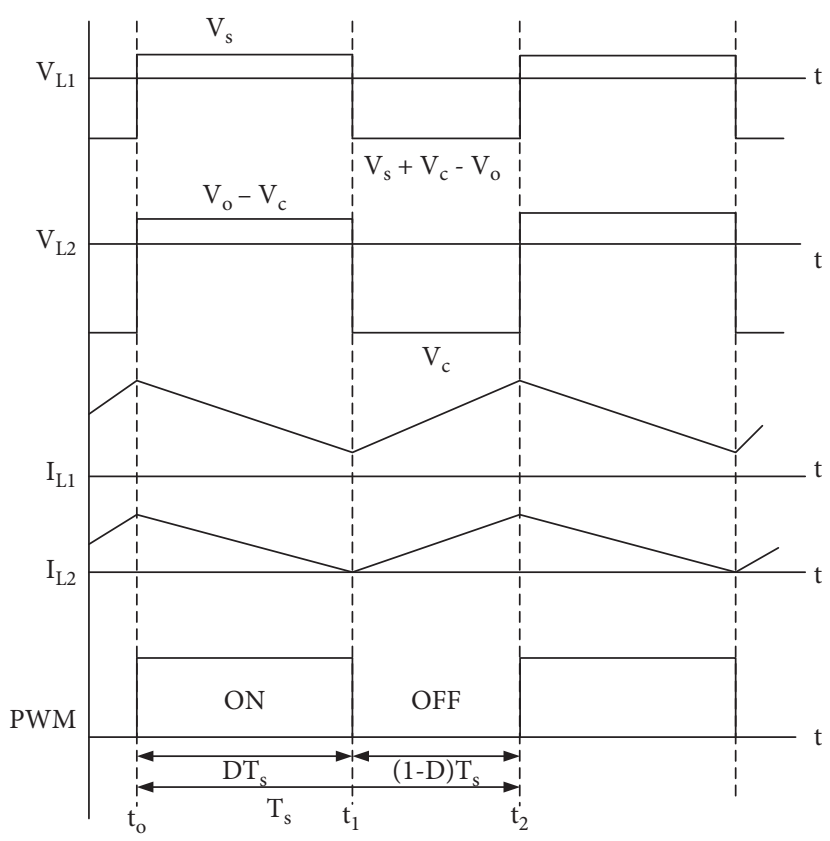

(a)

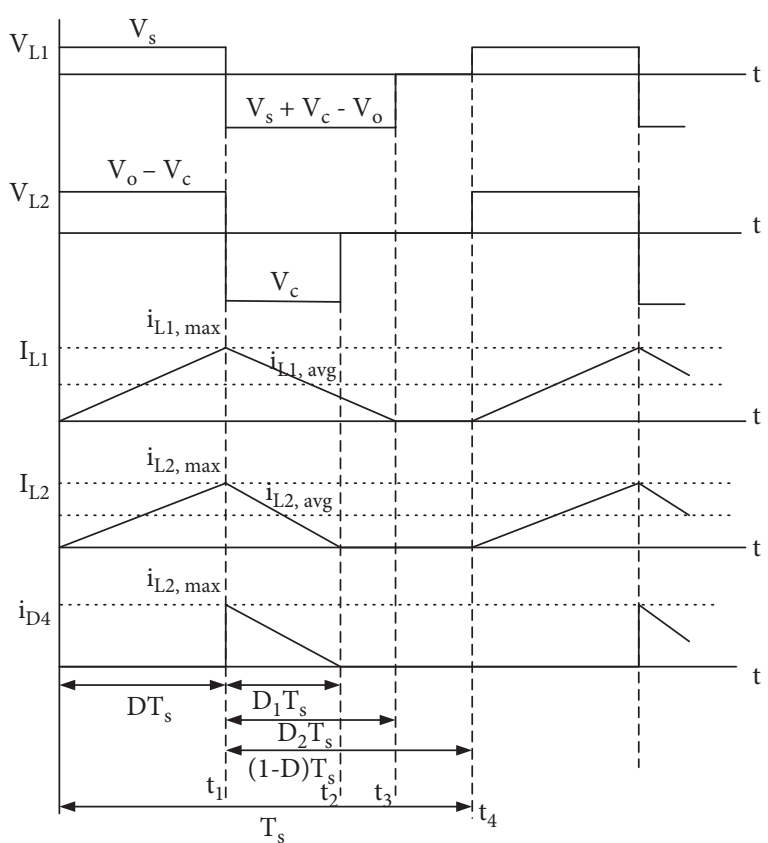

(b)

FiguRe 8: Working waveform of converter in boundary condition mode during step-up operation. (a) Boundary condition. (b) Discontinuous conduction. 


$$
L_{2} \geq \frac{V_{o}}{8 I_{\text {L2avg }} f_{s}} .
$$

Similiar methods can be used to calculate the value of inductor $L_{1}$. The critical value of inductor $L_{1}$ can be obtained as

$$
L_{1} \geq \frac{V_{o}}{2 I_{L 1 \mathrm{avg}} f_{s}} D(1-D)^{2} .
$$

The value of $D$ is obtained to maximize $L_{1}$ by calculating the first derivative of equation (14) with respect to $D$ and equals to zero. Then, the value of $D$ is obtained as $1 / 3$.

$$
L_{1} \geq \frac{2 V_{o}}{27 I_{\text {Llavg }} f_{s}} .
$$

Consider linear variation, capacitor $C_{1}$ can be calculated based on output current.

$$
\begin{aligned}
& I_{o}=C_{1} \frac{\Delta V_{o}}{\Delta t}, \\
& I_{o}=I_{L 1}(1-D)^{2}=I_{L 2}(1-D) .
\end{aligned}
$$

When switch $S_{2}$ is turned $\mathrm{ON}$, the value of $\Delta t=D T_{s}$, $T_{s}=1 / f_{s}$, and using equation (17), the capacitor $C_{1}$ is calculated as

$$
C_{1}=\frac{D I_{o}}{\Delta V_{o} f_{s}}=\frac{I_{L 1 \mathrm{avg}}}{\Delta V_{o} f_{s}} D(1-D)^{2} .
$$

The value of $D$ is obtained to maximize $C_{1}$ by calculating the first derivative of equation (18) with respect to $D$ and equals to zero. Then, the value of $D$ is obtained as $1 / 3$.

$$
C_{1}=\frac{4 I_{L 1 \mathrm{avg}}}{27 \Delta V_{o} f_{s}} .
$$

The value of capacitor $C_{o}$ is calculated as

$$
\begin{aligned}
I_{c o} & =C_{o} \frac{\Delta V_{c o}}{\delta t}, \\
I_{L 2}-I_{o} & =C_{o} \frac{\Delta V_{o}}{(1-D) T_{s}}, \\
C_{o} & =\frac{I_{L 1 \text { avg }}}{\Delta V_{o} f_{s}} D(1-D)^{2} .
\end{aligned}
$$

The value of duty cycle $D$ is obtained to maximize $C_{o}$ by calculating the first derivative of equation (22) with respect to $D$ and equals to zero. Then, the value of $D$ is obtained as $1 / 3$.

$$
C_{o}=\frac{4 I_{L 1 \mathrm{avg}}}{27 \Delta V_{o} f_{s}} .
$$

The voltage stress on switches $S_{1}, S_{2}, S_{3}$, and $S_{4}$ during step-up and step-down operation of converter are obtained as

$$
\begin{aligned}
& V_{S 1}=V_{S 3}=\frac{D V_{s}}{(1-D)}, \\
& V_{S 2}=V_{S 4}=\frac{V_{s}}{(1-D)^{2}} .
\end{aligned}
$$

The different stages for the discontinuous conduction mode (DCM) in step-up operation are explained as follows. In DCM, there are four stages, the first stage is alike to CCM and no need to be explained it again. In second stage, when all the energy stored in $L_{2}$ is transferred to load and current through $D_{4}$ become zero at $t_{2}$ before next switch $S_{2}$ is ON. In the third stage, all the energy stored in $L_{1}$ is transferred to capacitor $C_{1}$ and current through $D_{3}$ becomes zero at $t_{3}$ before switch $S_{1}$ is ON. Figure 8(b) shows the working waveform of the four stages in DCM. As per this, at steady state, the average diode current $i_{D 4}$ over one switching period is equal to $i_{L 2, \text { avg }}$.

$$
I_{o}=i_{D 4, \mathrm{avg}}=\frac{i_{L 2, \max }}{2} D_{1},
$$

The voltage across $L_{1}$ and $L_{2}$ considering step-up and DCM operation

$$
\begin{array}{r}
D V_{s}+(1-D)\left(V_{s}+V_{c}-V_{o}\right)=0, \\
D\left(V_{c}-V_{o}\right)+D_{1} V_{C}=0 .
\end{array}
$$

The voltage gain in DCM is calculated as

$$
\frac{V_{o}}{V_{s}}=\frac{\left(D+D_{1}\right)}{\left(D+D_{1}\right)(1-D)+D(D-1)} .
$$

The equivalent load resistance as $R_{o}$ and substituting (17) into (25), and using (25), the duty $D_{1}$ is given by

$$
D_{1}=\frac{2 L_{2} f_{s}(1-D)}{R_{o} D} \text {. }
$$

From working waveform of Figure 8(b), it is observed from the DCM operation that it is required that

$$
D_{1}<(1-D) \text {. }
$$

Thus, the critical value of the duty cycle to avoid the converter operates in DCM is given by

$$
D>\frac{2 L_{2} f_{s}}{R_{o}} \text {. }
$$

3.2. Stability Analysis. The stability of any system is defined as the ability to produce bounded output when a bounded input is applied to it. The general state space representation of a system is given by

$$
\begin{aligned}
& \dot{x}(t)=A x(t)+B u(t), \\
& y(t)=C x(t)+D u(t) .
\end{aligned}
$$

The state space equation of the converter in step-up for $\mathrm{ON}$ and OFF condition is 
TABle 1: Converter parameters.

\begin{tabular}{lc}
\hline Parameter & Value \\
\hline$P_{o}$ & $1 \mathrm{~kW}$ \\
$V_{o}$ & $200 \mathrm{~V}$ \\
$f_{s}$ & $20 \mathrm{kHz}$ \\
$L_{1}$ & $0.37 \mathrm{mH}$ \\
$L_{2}$ & $1.25 \mathrm{mH}$ \\
$C_{1}$ & $47 \mu \mathrm{F}$ \\
$C_{o}$ & $100 \mu \mathrm{F}$ \\
\hline
\end{tabular}

$\dot{x}(t)=A_{1} x(t)+B_{1} x(t)$

$\left(\begin{array}{c}i_{L 1} \\ i_{L 2} \\ \dot{v}_{c} \\ v_{c o}\end{array}\right)=\left(\begin{array}{cccc}0 & 0 & 0 & 0 \\ 0 & 0 & \frac{1}{L_{2}} & \frac{-1}{L_{2}} \\ 0 & \frac{1}{C_{1}} & 0 & 0 \\ i_{L 2} \\ v_{c} \\ \frac{-1}{C_{o}} & 0 & \frac{-1}{R_{o} C_{o}}\end{array}\right)+\left(\begin{array}{c}i_{L 1} \\ v_{c o}\end{array}\right)\left(\begin{array}{c}\frac{1}{L_{1}} \\ 0 \\ 0 \\ 0\end{array}\right)\left(v_{s}\right)$

$\dot{x}(t)=A_{2} x(t)+B_{2} x(t)$

$\left(\begin{array}{c}i_{L 1} \\ i_{L 2} \\ \dot{v}_{c} \\ v_{c o}\end{array}\right)=\left(\begin{array}{cccc}0 & 0 & \frac{1}{L_{1}} & \frac{-1}{L_{1}} \\ 0 & 0 & \frac{-1}{L_{2}} & 0 \\ \frac{-1}{C_{1}} & \frac{1}{C_{1}} & 0 & 0 \\ \frac{1}{C_{o}} & 0 & 0 & \frac{-1}{R_{o} C_{o}}\end{array}\right)\left(\begin{array}{c}i_{L 1} \\ i_{L 2} \\ v_{c} \\ v_{c o}\end{array}\right)+\left(\begin{array}{c}\frac{1}{L_{1}} \\ 0 \\ 0 \\ 0\end{array}\right)\left(v_{s}\right)$

$y(t)=C_{1} x(t)+D_{1} u(t)$

$y(t)=C_{2} x(t)+D_{2} u(t)$

$\left(v_{o}\right)=\left(\begin{array}{llll}0 & 0 & 0 & 1\end{array}\right)\left(\begin{array}{c}i_{L 1} \\ i_{L 2} \\ v_{c} \\ v_{c o}\end{array}\right)+(0)\left(v_{s}\right)$.

$(32)$

$$
\begin{aligned}
A & =A_{1} D+A_{2}(1-D), \\
B & =B_{1} D+B_{2}(1-D), \\
A & =\left(\begin{array}{cccc}
0 & 0 & \frac{(1-D)}{L_{1}} & \frac{-(1-D)}{L_{1}} \\
0 & 0 & \frac{-1}{L_{2}} & \frac{D}{L_{2}} \\
\frac{-(1-D)}{C_{1}} & \frac{1}{C_{1}} & 0 & 0 \\
\frac{(1-D)}{C_{o}} & \frac{(-D)}{C_{o}} & 0 & \frac{-1}{R_{o} C_{o}}
\end{array}\right), \\
C & =\left(\begin{array}{ccc}
0 & 1 \\
D & 0
\end{array}\right), \\
B & =\left(\begin{array}{c}
0 \\
0 \\
L_{1}
\end{array}\right),
\end{aligned}
$$

Small signal model is derived by applying perturbations, and the overall state and output equation of the converter is obtained as2

$$
\begin{aligned}
& \left(\begin{array}{c}
\tilde{i_{L 1}} \\
\widetilde{i_{L 2}} \\
\widetilde{v_{c}} \\
\widetilde{v_{c o}}
\end{array}\right)=\left(\begin{array}{cccc}
0 & 0 & \frac{(1-D)}{L_{1}} & \frac{-(1-D)}{L_{1}} \\
0 & 0 & \frac{-1}{L_{2}} & \frac{D}{L_{2}} \\
\frac{-(1-D)}{C_{1}} & \frac{1}{C_{1}} & 0 & 0 \\
\frac{(1-D)}{C_{o}} & \frac{-D}{C_{o}} & 0 & \frac{-1}{R_{o} C_{o}}
\end{array}\right)\left(\begin{array}{c}
\widetilde{i_{L 1}} \\
\widetilde{i_{L 2}} \\
\tilde{v_{c}} \\
\widetilde{v_{c o}}
\end{array}\right) \\
& +\left(\begin{array}{cc}
\frac{v_{c o}-v_{c}}{L_{1}} & \frac{1}{L_{1}} \\
\frac{v_{c o}}{L_{2}} & 0 \\
\frac{i_{L 1}}{C_{1}} & 0 \\
\frac{-\left(i_{L 1}-i_{L 2}\right)}{C_{o}} & 0
\end{array}\right)\left(\begin{array}{c}
\tilde{d} \\
\tilde{v}_{s}
\end{array}\right)
\end{aligned}
$$

Now, applying the state-space averaging technique, 
After substituting all passive elements value from Table 1 and duty cycle $D=0.51$, duty to output voltage transfer function $G(s)$ is obtained as follows:

$$
G(s)=\frac{\widetilde{v_{o}(s)}}{\widetilde{d(s)}}=\frac{-3.46 \times 10^{5} s^{3}+5.38 \times 10^{8} s^{2}-5.45 \times 10^{12} s+2.42 \times 10^{16}}{1.11 s^{4}+2.8 \times 10^{2} s^{3}+4.4 \times 10^{7} s^{2}+8.6 \times 10^{9} s+2.96 \times 10^{13}} .
$$

From the above transfer function, it is observed that the all the poles and two zeros lie on the left half and one zero lies on the right half of S-plane of in root locus. Transfer function of a PI controller is

$$
G_{\mathrm{PI}}=\frac{K_{p} s+K_{i}}{s}
$$

Ziegler-Nichols' closed loop tunning method is used to tune the PI controller, the value of $K_{p}=1.93 \times 10^{-4}$ and $K_{i}=0.172$ substituted in (36), and therefore, the closed loop transfer function (CLTF) of the converter is obtained as follows:

$$
\operatorname{CLTF}=\frac{\widetilde{v_{o}(s)}}{\widetilde{d(s)}}=\frac{-66.91 s^{4}+4.42 \times 10^{4} s^{3}-9.6 \times 10^{8} s^{2}+3.73 \times 10^{12} s+4.16 \times 10^{15}}{s\left(1.11 s^{4}+2.8 \times 10^{2} s^{3}+4.4 \times 10^{7} s^{2}+8.6 \times 10^{9} s+2.96 \times 10^{13}\right)}
$$

The magnitude and phase plot is obtained from CLTF are shown in Figure 9. In magnitude plot, there two updown glitch, and it occurs due to two pair of complex conjugate pole $\left(P_{1,2}=-26.8 \pm j 6243, P_{3,4}=-99.1 \pm j 821\right)$ and one pair of conjugate zero $\left(Z_{1,2}=-860 \pm j 4544\right)$ in the open loop transfer function $G(s)$ of the converter. From Bode diagram, one can see phase margin $\left(\mathrm{PM}=40.8^{\circ}\right)$ and gain margin $(G M=2.81 \mathrm{~dB})$, so it can say that the system is stable.

\section{Computational and Experimental Results}

4.1. Computational Results. The bidirectional quadratic converter along with VSI for the PMBLDC machine is simulated in MATLAB/Simulink. The vehicular load is simulated through a pulley and belt during motoring operation and an inertial load of $0.1 \mathrm{~kg} \cdot \mathrm{m}^{2}$ during regenerative braking operation. The PMBLDC machine having parameters is given in Table 2 . The proposed converter is simulated and designed for $1 \mathrm{~kW}$ power at an output voltage of $200 \mathrm{~V}$ with battery voltage at $48 \mathrm{~V}$ and switching frequency of $20 \mathrm{kHz}$. The DC-DC converter and inverter switching PWM generated in MATLAB simulink are illustrated in Figures 10(a) and 10(b), respectively. The parameters of the converter are calculated, and its value is given in Table 1 . The type of battery used in experimental setup and its parameters is given in Table 3.

The system is simulated for $5 \mathrm{~s}$ with $0 \mathrm{~s}$ to $3 \mathrm{~s}$ in step-up (motoring) and $3 \mathrm{~s}$ to $5 \mathrm{~s}$ in the step-down (RB) mode. The steady-state inductor's current in the converter's step-up operation is shown in Figure 11(a), and the step-down operation is shown in Figure 11(b). In step up, when switches $S_{1}$ and $S_{2}$ are ON, both inductor's current increases and OFF both inductor's current decreases. Similarly, in step down, when switches $S_{3}$ and $S_{4}$ are ON, both inductor's current increases, and when it is OFF, both inductor's current decreases and both inductor current is negative. The steady-state output voltage $V_{o}$, capacitor $C_{1}$, capacitor voltage $V_{c}$, and battery voltage $V_{s}$ during step-up operation of converter are shown in Figure 12. The battery voltage $V_{s}=48 \mathrm{~V}$, capacitor voltage $V_{c}=102 \mathrm{~V}$, and output $V_{o}=$ $220 \mathrm{~V}$ at duty cycle $51 \%$ can be seen in Figure 12 .

The voltage stress on switches $S_{1}, S_{2}, S_{3}$, and $S_{4}$ during converter's step-up operation are shown in Figure 13. $V_{s 1}=$ $V_{s 3}=100 \mathrm{~V}$ are voltage stresses on switches $S_{1}$ and $S_{3}$, respectively, and voltage stress on switch $S_{2}$ and $S_{4}$ are $V_{s 2}=$ $V_{s 4}=200 \mathrm{~V}$ (Figures 13(a) and 13(b)). The speed characteristics of PMBLDC machine during motoring mode from time $0 \mathrm{~s}$ to $3 \mathrm{~s}$ are illustrated in Figure 14. From graphical descriptions, the speed of motor reaches up to $3600 \mathrm{rpm}$ at time $3 \mathrm{~s}$. The RB is applied to reduce the motor speed from $3600 \mathrm{rpm}$ to $500 \mathrm{rpm}$ as described in Figure 14.

The stator current of PMBLDC machine when it acts as motor can be seen in Figure 15(a) and when it act as generator can be seen in Figure 15(b).

4.2. Hardware Results. A model of the proposed converter is designed and developed for the experimental validation as shown in Figure 16. The converter component's values used in the prototype are the same as chosen in simulation parameters.

In this paper, the control strategy is realized by using the TMS320F28335 DSP microcontroller for proposed converter and driving PMBLDC machine in both motoring and RB. A PMBLDC machine coupled with a flywheel is used to emulate the RB action. To reduce the impulse torque condition and safety of the system, a pulley belt system is employed for mechanical coupling of the motor and inertial load. Figure 17 shows the system voltages in steady-state, battery voltage $V_{s}=50 \mathrm{~V}$, capacitor voltage $V_{c}=100 \mathrm{~V}$, and output voltage $V_{o}=200 \mathrm{~V}$ in step-up operation of converter. 

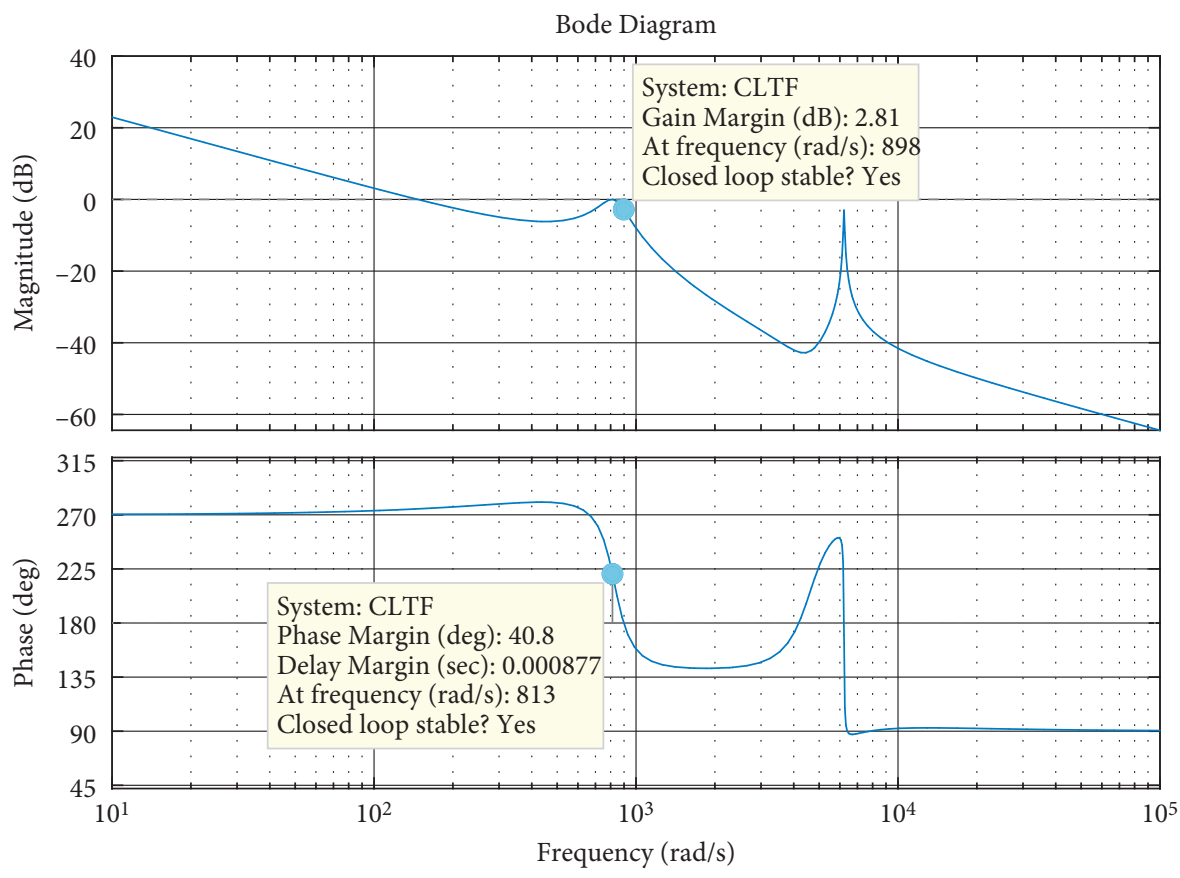

Figure 9: Magnitude and phase plot is obtained from CLTF.

TABle 2: Motor parameters.

\begin{tabular}{lc}
\hline Parameter & Value \\
\hline Rated power & $1 \mathrm{hp}$ \\
Per phase resistance $\left(R_{a}\right)$ & $1.09 \Omega$ \\
Per phase inductance $\left(L_{a}\right)$ & $3.37 \mathrm{mH}$ \\
Voltage constant $(K)$ & $51.3 \mathrm{~V} / \mathrm{krpm}$ \\
Inertia $(J)$ & $0.00014 \mathrm{~kg} \cdot \mathrm{m}^{2}$ \\
Pole pair $(P)$ & 2 \\
\hline
\end{tabular}

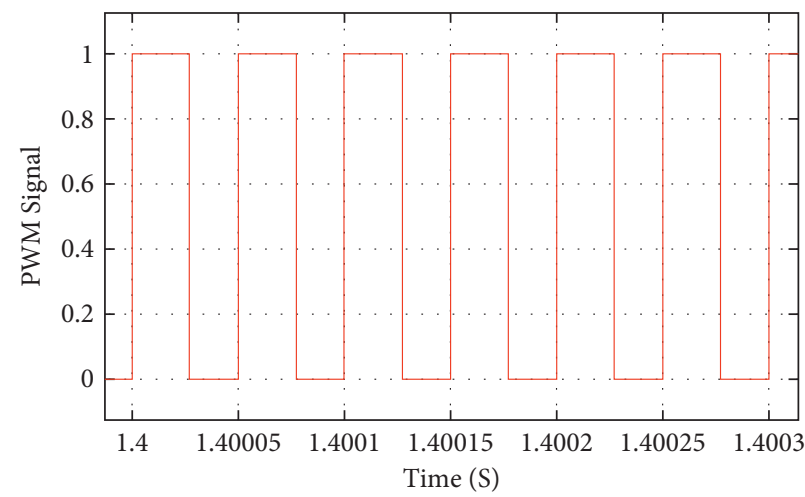

(a)

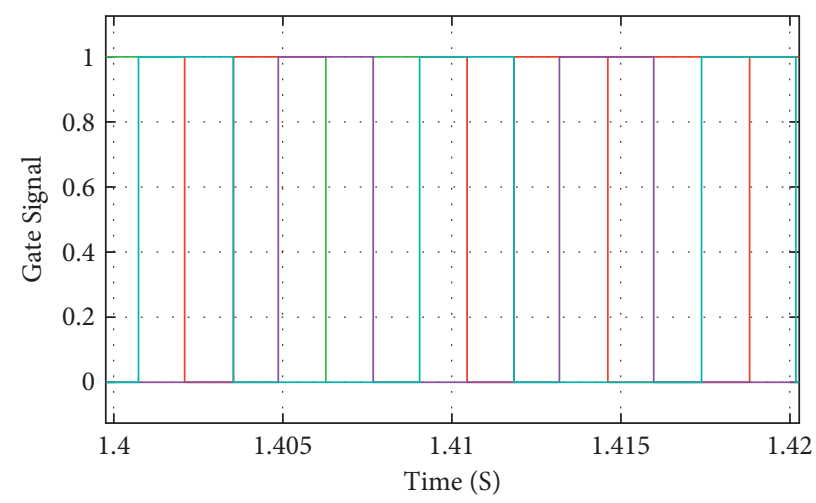

$\begin{array}{rr}\text { g1 } & -\mathrm{g} 4 \\ \mathrm{~g} 2 & -\mathrm{g} 5 \\ \mathrm{~g} 3 & -\mathrm{g} 6\end{array}$

(b)

FIGURE 10: Switching signal of DC-DC converter and inverter in MATLAB Simulink. (a) Switching PWM of DC-DC converter. (b) Switching PWM of inverter.

The steady-state inductors current $I_{L 1}$ and $I_{L 2}$ during step-up operation of converter are shown in Figure 18. In step-up operation of converter, the steady-state inductor $L_{1}$ current $I_{L 1}=10.5 \mathrm{~A}$ and inductor $L_{2}$ current $I_{L 2}=5.25 \mathrm{~A}$ can be seen in Figure 18. The inductor current at discontinuous condition mode and boundary condition mode is shown in 
TABLE 3: Battery parameters.

\begin{tabular}{lc}
\hline Parameter & Value \\
\hline Type & Li-NMC \\
Open circuit voltage & $50.5 \mathrm{~V}$ \\
$\%$ SOC & $90 \%$ \\
Ah rating & $25 \mathrm{Ah}$ \\
Nominal discharge current & $10 \mathrm{~A}$ \\
\hline
\end{tabular}
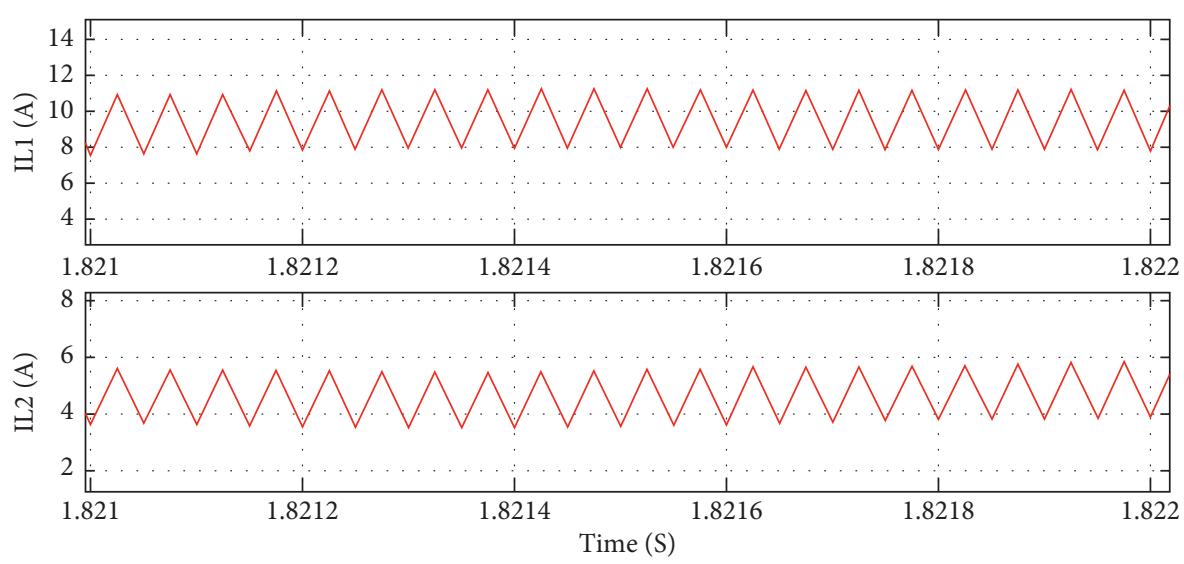

(a)
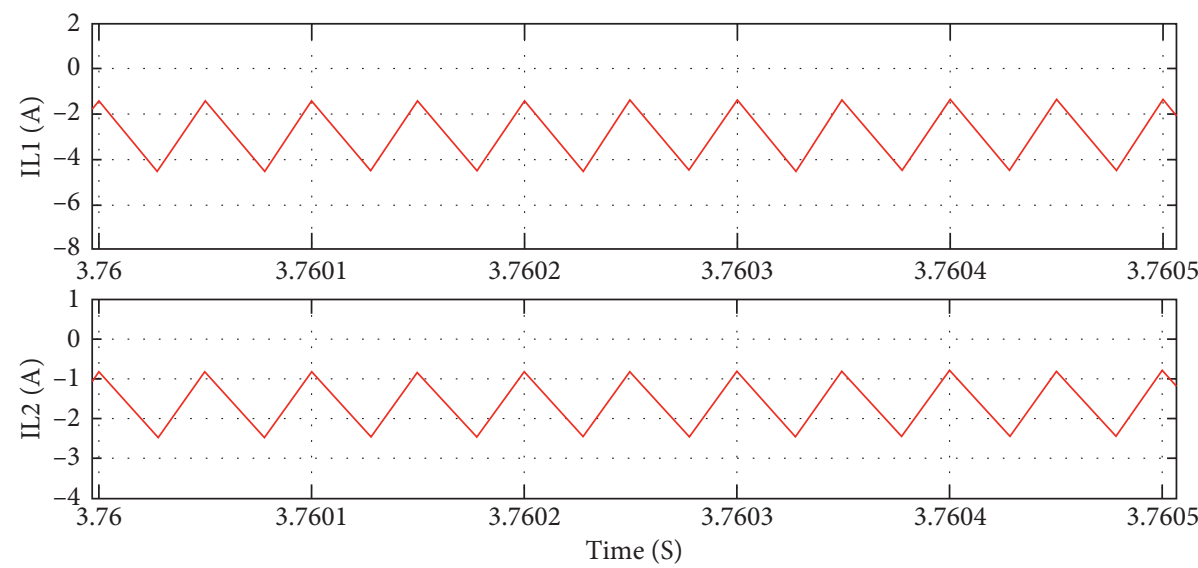

(b)

FIgURE 11: Inductor's current during (a) step-up and (b) step-down operation of the converter.
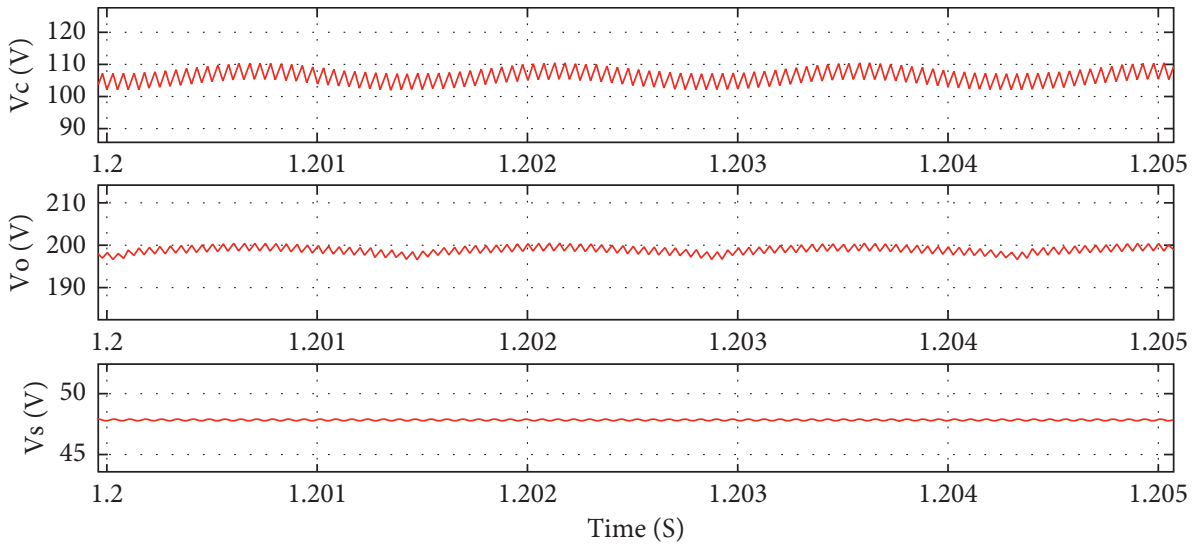

FIGURE 12: Steady-state voltages in converter's step-up operation. 


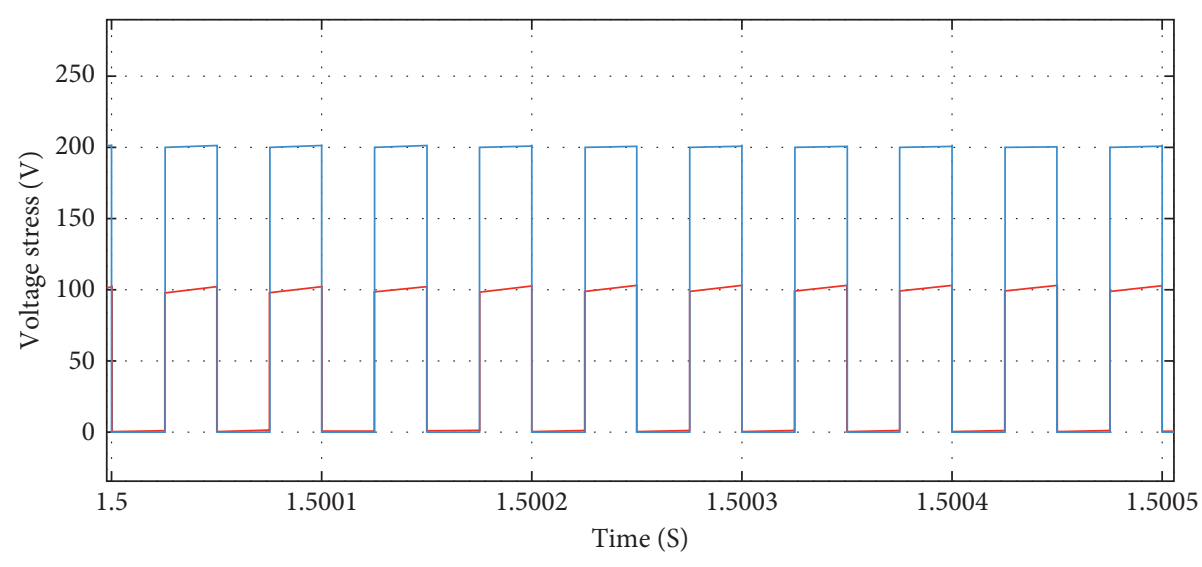

Vs1
Vs2

(a)

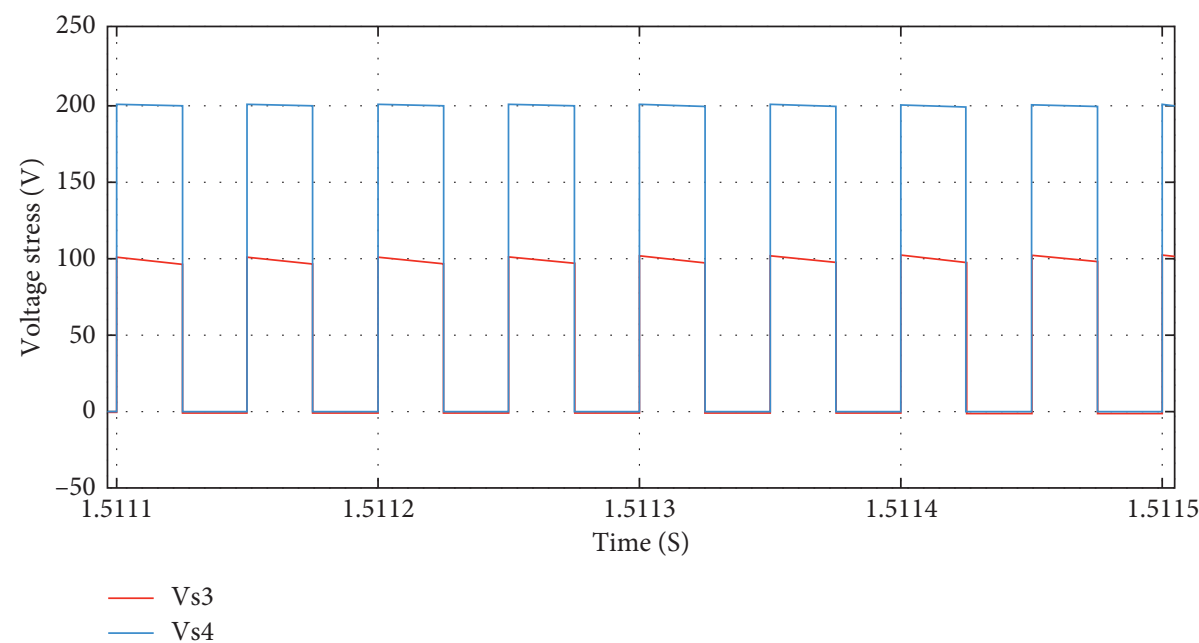

(b)

FIgURE 13: Illustration of voltage stress on all switches. (a) Voltage stress on switch $S_{1}$ and $S_{2}$. (b) Voltage stress on switch $S_{3}$ and $S_{4}$.

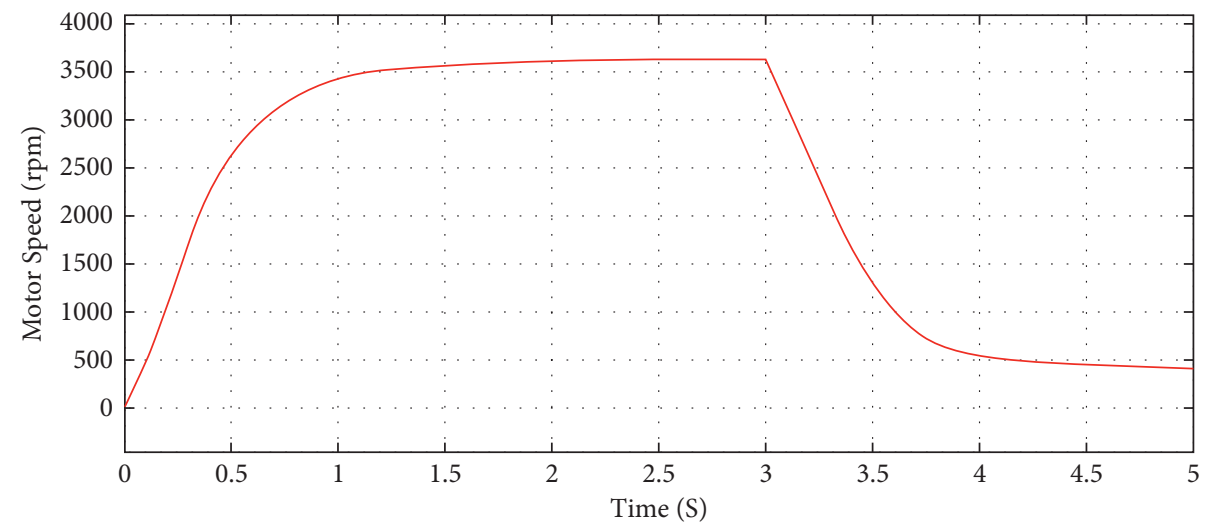

FIgURE 14: PMBLDC machine speed characteristics.

Figures 19(a) and 19(b), respectively. The PMBLDC machine is coupled with pulley, and in order to apply load torque, a belt which is connected through a digital weighing machine at the both end. The steady-state three phase stator current of PMBLDC machine in motoring mode during converter's step-up operation is shown in Figure 20. 


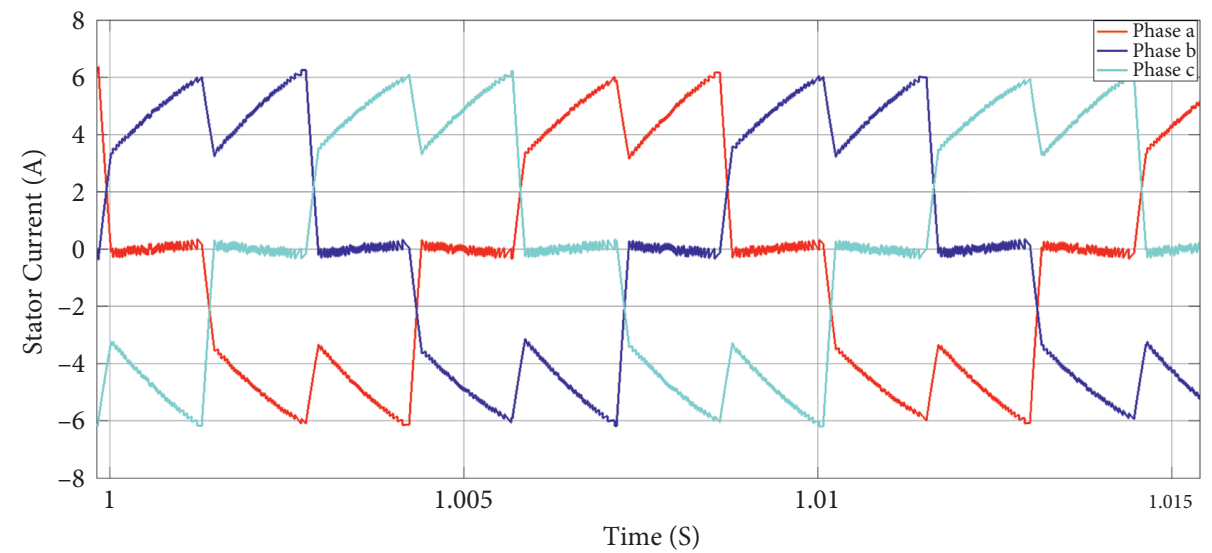

(a)

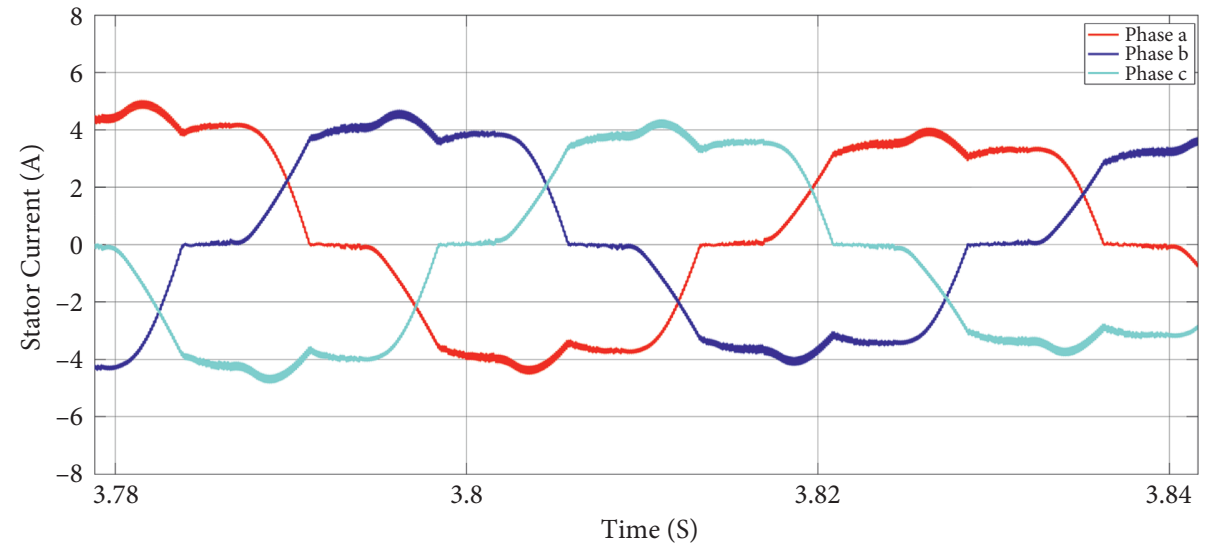

(b)

FIGURE 15: Illustration of current of the stator of PMBLDC machine. (a) When act as motor. (b) When act as generator.

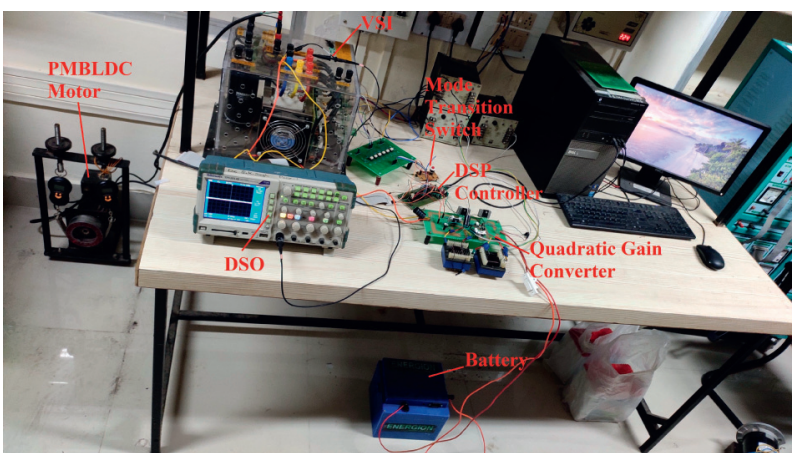

FigURE 16: Experimental setup.

A load torque of $1.5 \mathrm{~N}-\mathrm{M}$ is applied on PMBLDC machine through belt, and all three phase currents $I_{a}=I_{b}=$ $I_{c}=4 \mathrm{~A}$ are flowing which is shown in Figure 20.

The voltage stress on switches $S_{1}$ and $S_{2}$ are shown in Figure 21 and switches $S_{3}$ and $S_{4}$ are shown in Figure 22 during converter's step-up operation. In the step-down operation of the converter, the PMBLDC machine is loaded with a flywheel to show the power flow from load to battery during $\mathrm{RB}$. A physical mode transition switched is used to change the mode of operation from motoring to $\mathrm{RB}$ and vice-versa. When $\mathrm{RB}$ is applied

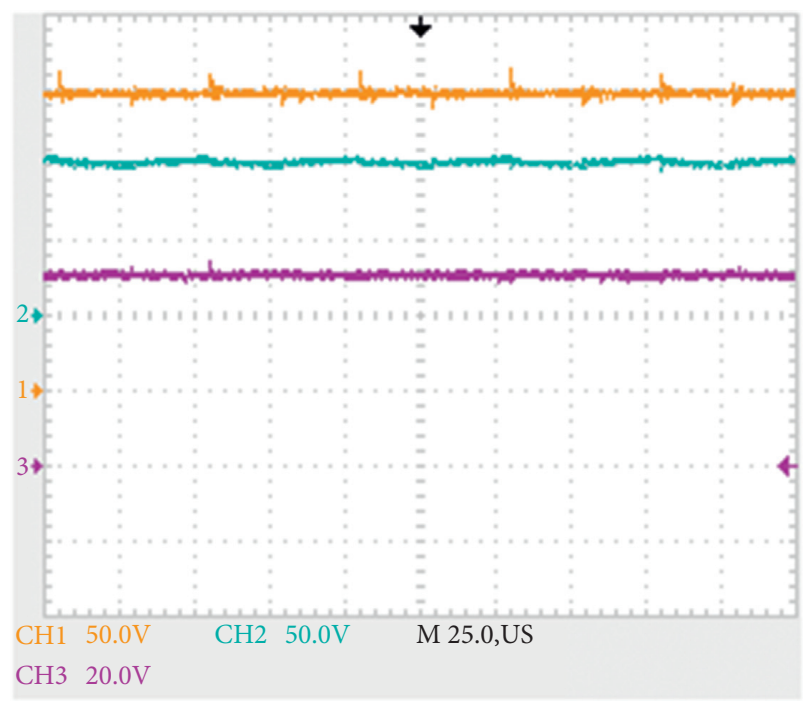

FIGURE 17: Plot of system battery voltage (channel-2), capacitor voltage (channel-3), and output voltage (channel-1) during step-up operation.

through the mode transition switch, the change in the inductor's current and output voltage of the converter is shown in Figure 23. 


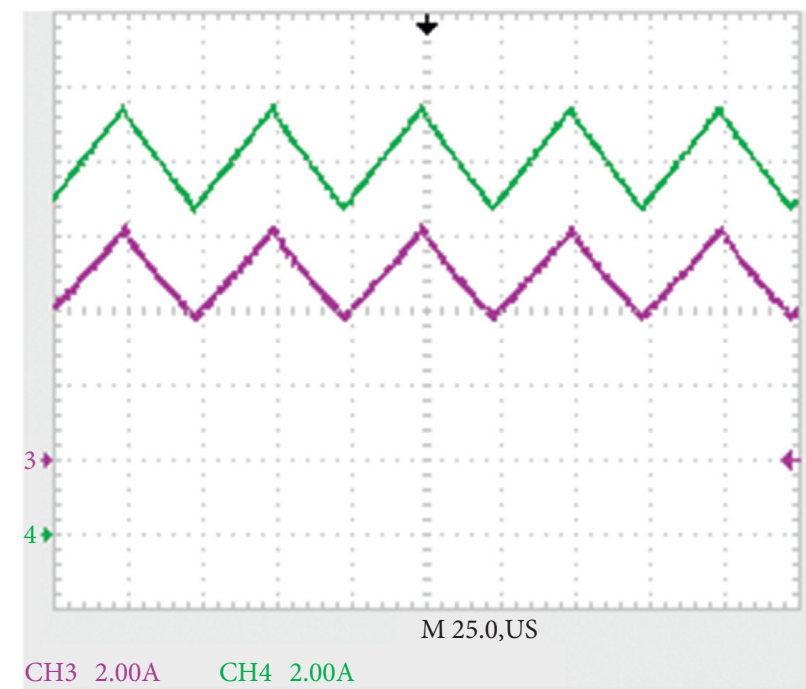

Figure 18: Plot of steady-state inductor current $I_{L 1}$ (channel-4) and $I_{L 2}$ (channel-3) during step-up operation.

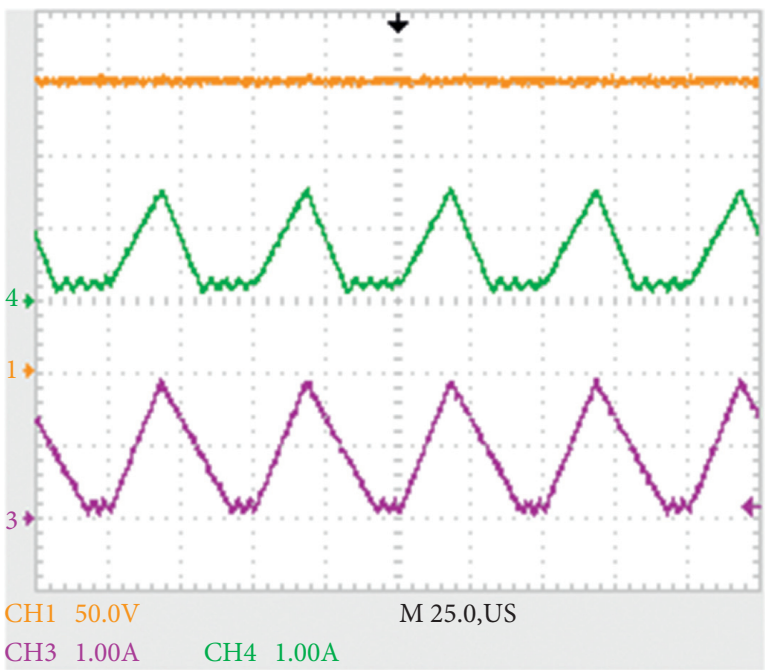

(a)

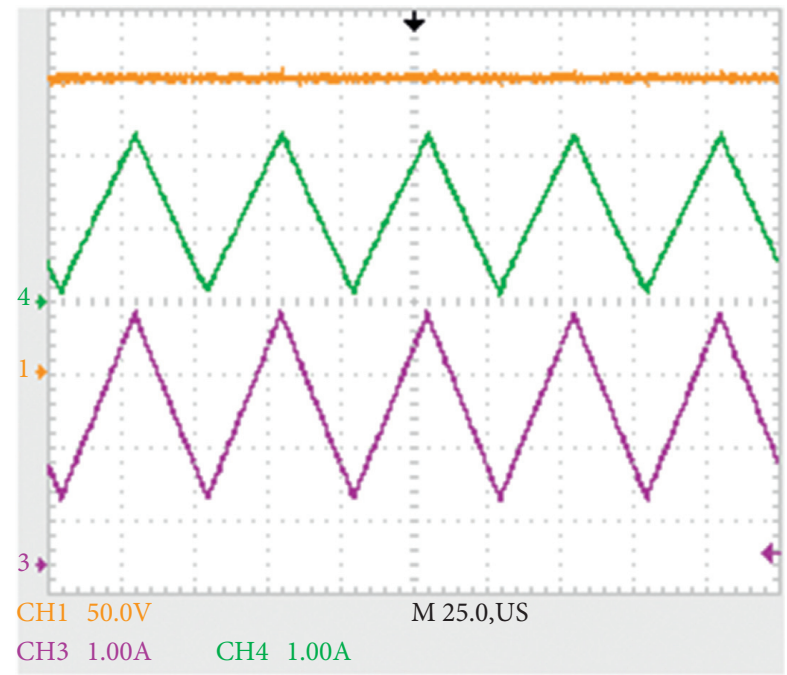

(b)

FIGURE 19: Inductor's current in (a) discontinuous conduction mode and (b) boundary condition mode. (a) Inductor's current $I_{L 1}$ (channel-3), $I_{L 2}$ (channel-4), and output voltage $V_{o}$ (channel-1). (b) Inductor's current $I_{L 1}$ (channel-3), $I_{L 2}$ (channel-4), and output voltage $V_{o}$ (channel-1).

Figure 24 show the inductor $L_{1}$ and $L_{2}$ current during step-down operation of converter, and it is negative which means power is flowing from load to source. The steady-state inductor $L_{1}$ current $I_{L 1}=-3 \mathrm{~A}$ and inductor $L_{2}$ current $I_{L 2}=$ $-1.5 \mathrm{~A}$ during $\mathrm{RB}$ of PMBLDC machine and converter operate in step-down. The stator current of PMBLDC motor during RB is shown in Figure 25. A compression of different BDCs is done in Table 4. Efficiency curve of the converter in step-up and step-down operation is shown in Figures 26 and 27 , respectively. 


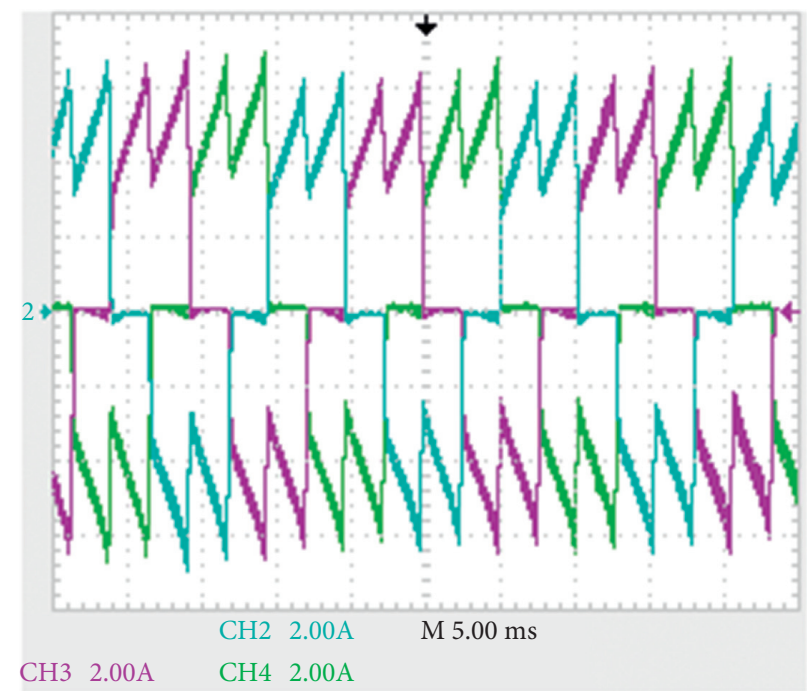

FIgURE 20: Steady-state three phase stator current of PMBLDC machine in motoring mode.

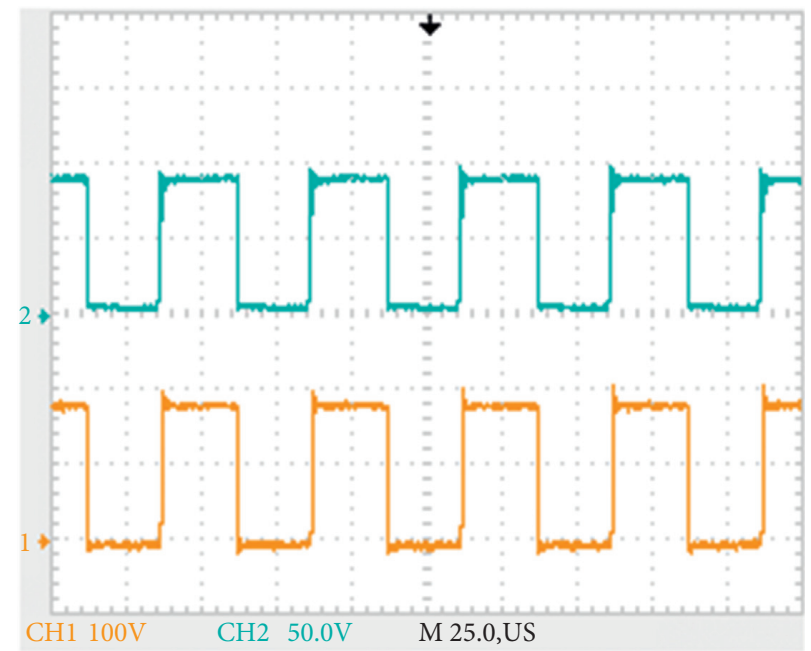

FIgURe 21: Plot of voltage stress on switches $V_{s 1}$ (channel-2) and $V_{s 2}$ (channel-1).

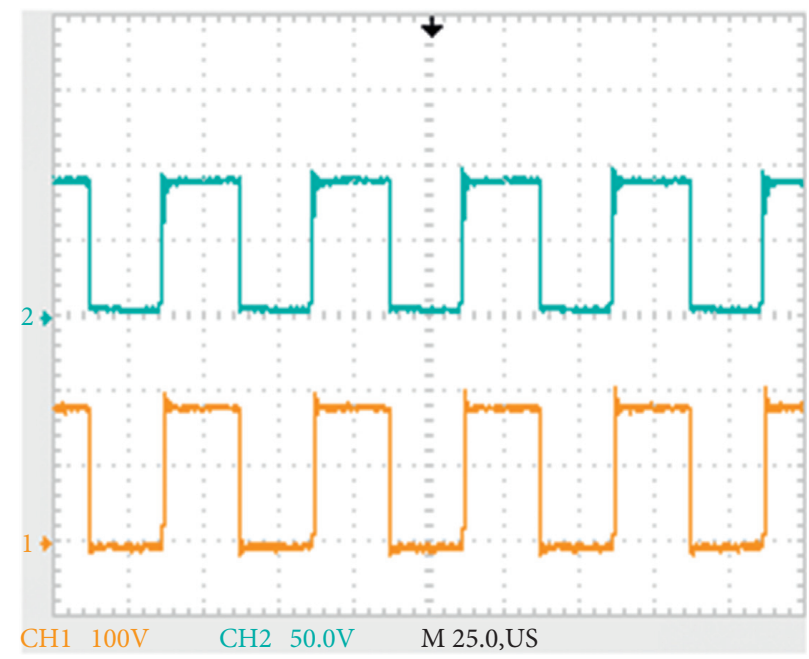

FIgUre 22: Plot of voltage stress on switches $V_{s 3}$ (channel-2) and $V_{s 4}$ (channel-1). 


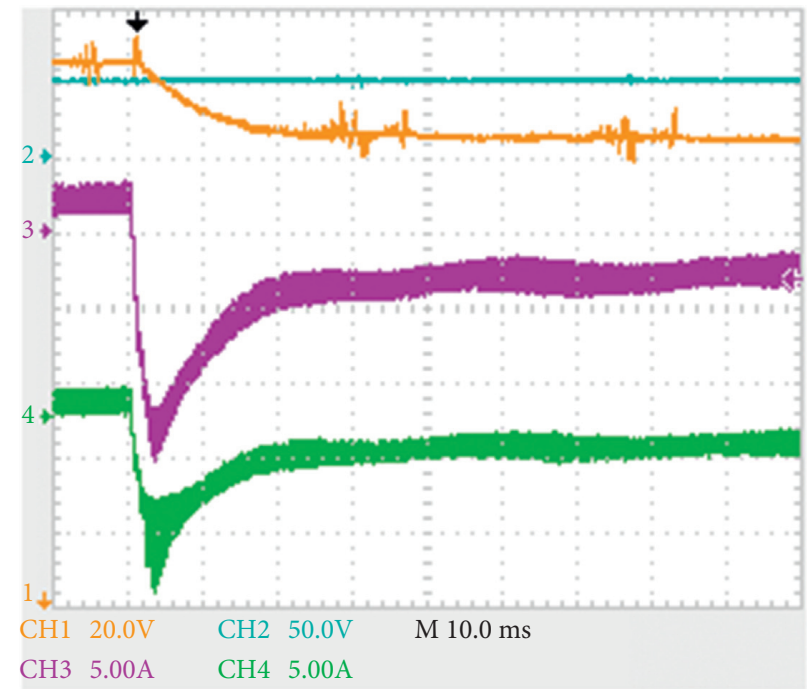

FIgURE 23: Inductor current $I_{L 1}$ (channel-3), $I_{L 2}$ (channel-4), and output voltage $V_{o}$ (channel-1) when RB is applied.

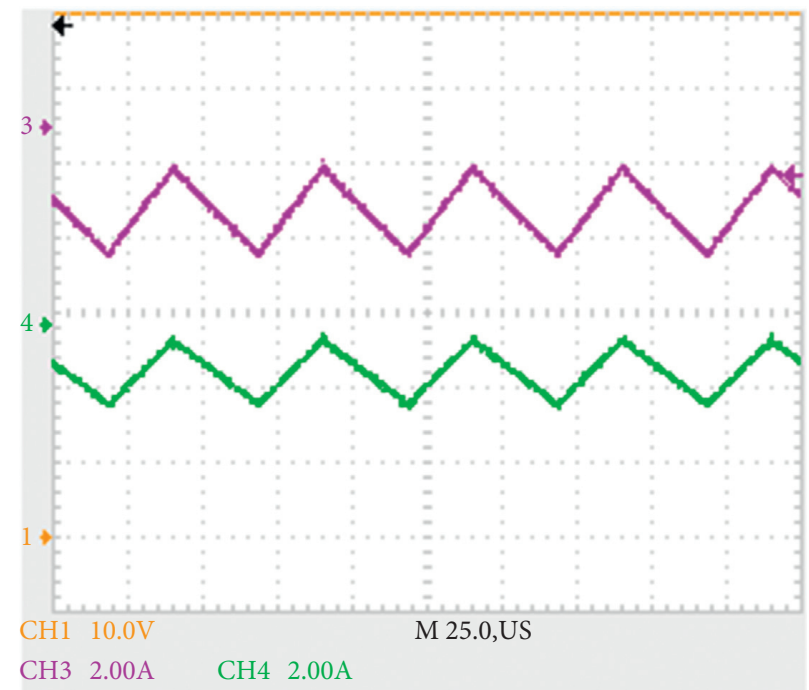

FIGURE 24: Inductor's current $I_{L 1}$ (channel-3) and $I_{L 2}$ (channel-4) during step-down operation of converter.

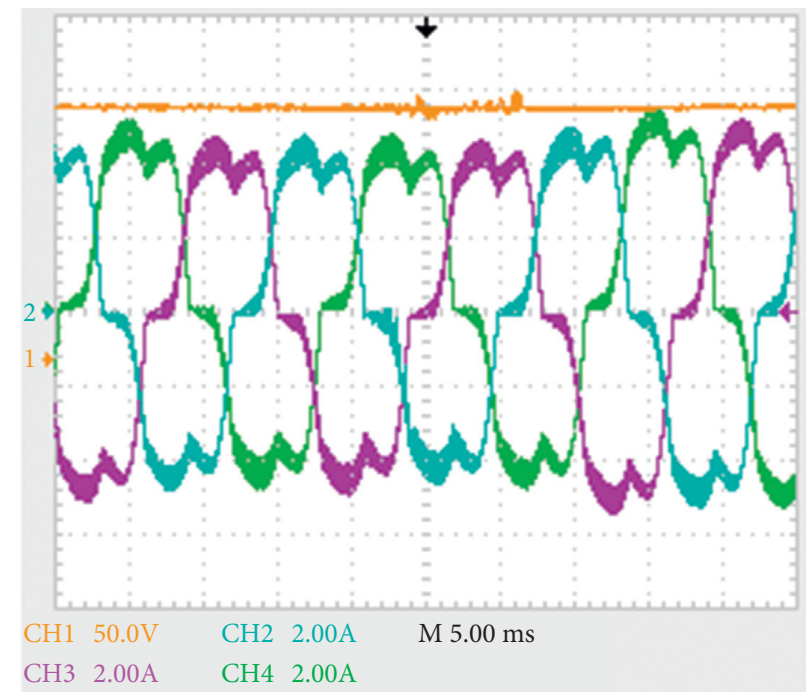

FIGURE 25: Three phase stator current $I_{a}$ (channel-2), $I_{b}$ (channel-3), $I_{c}$ (channel-4), and $V_{o}$ (channel-1) during regenerative braking. 


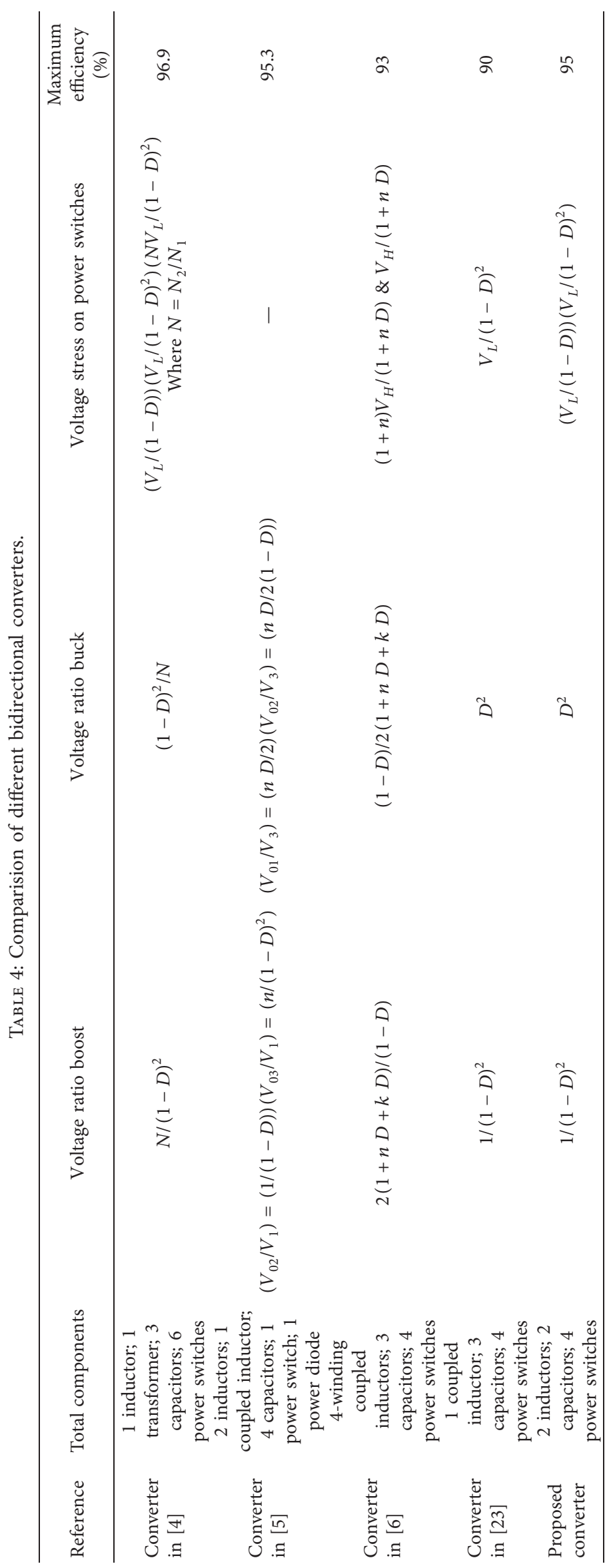




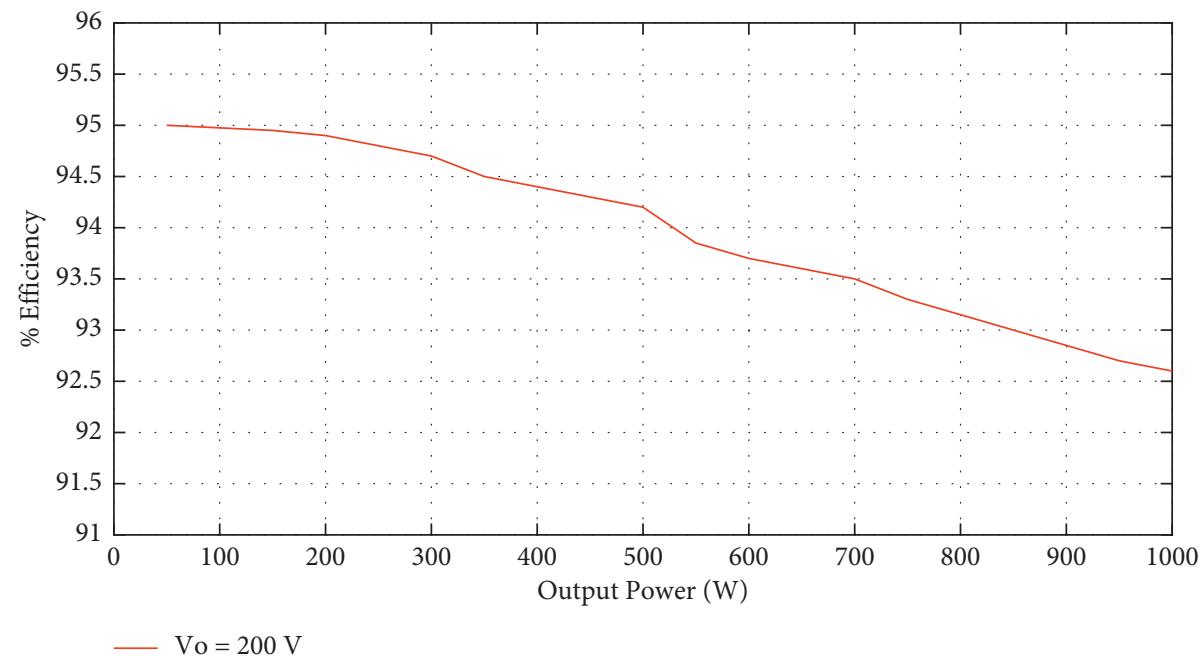

FIGURE 26: Converter efficiency during step-up operation at output voltage $V_{o}=200 \mathrm{~V}$ and input voltage $V_{s}=48 \mathrm{~V}$.

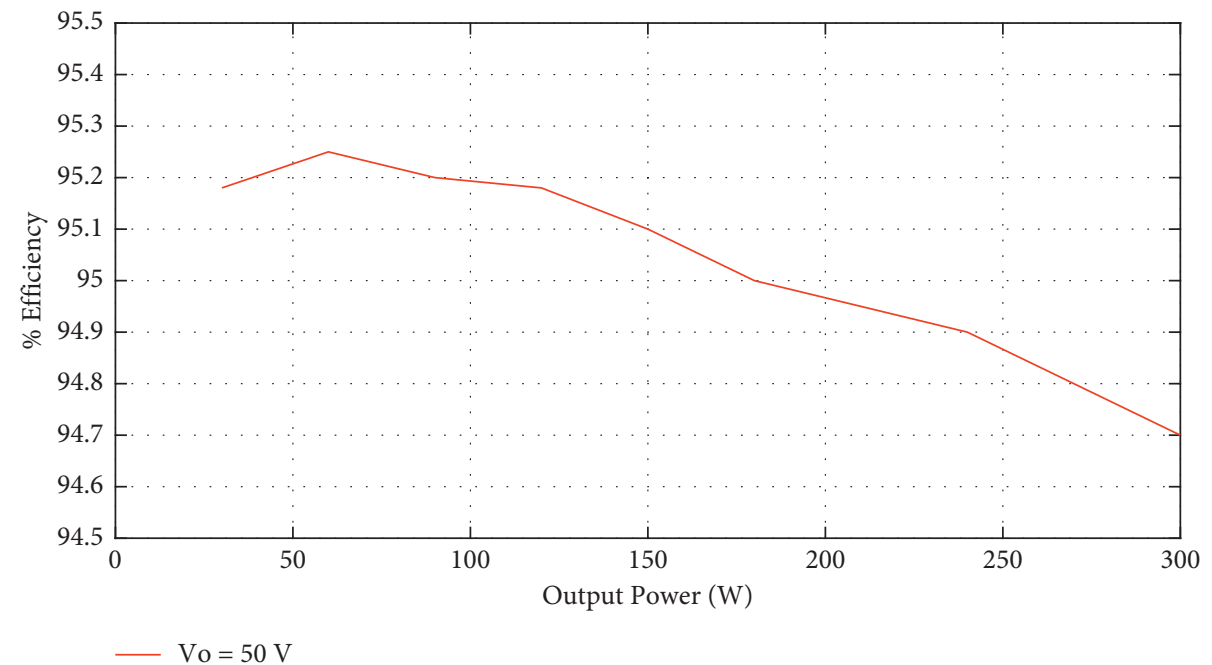

FIgURE 27: Converter efficiency during step-down operation at output voltage $V_{o}=50 \mathrm{~V}$ and input voltage $V_{s}=200 \mathrm{~V}$.

\section{Conclusion}

A QGBC is designed, developed, and tested for RB application in EV. The power flow direction is controlled successfully by changing the working mode of the VSI and the QGBC. In the regenerative braking mode, the inertial load's mechanical energy is changed to electrical energy and fed back to the battery, as evident from the results. A control strategy is implemented to boost the back EMF of the PMBLDC motor by controlling the VSI and using the selfinductance of the motor. The quadratic gain bidirectional DC-DC converter operates at maximum efficiency of $95 \%$ at an output voltage of $200 \mathrm{~V}$ during the converter's step-up operation. The implemented strategy and the system configuration present a frugal and practical approach to eliminate the drawbacks of regenerative braking in the buck mode of BDC.

$\begin{array}{ll}\text { Abbreviations } \\ V_{1}: & \text { Input voltage } \\ V_{o}: & \text { Output voltage } \\ V_{c 1}: & \text { Voltage across capacitor } C_{1} \\ D_{1,2}: & \text { Diode } \\ L_{1,2}: & \text { Inductor } \\ C_{1, o}: & \text { Capacitor } \\ S_{1,2,3,4}: & \text { Switch } \\ \mathrm{D}: & \text { Duty ratio } \\ I_{L 1,2}: & \text { Inductor current } \\ I_{c 1, c o}: & \text { Capacitor current } \\ \mathrm{J}: & \text { Moment of inertia } \\ T_{1,2,3,4,5,6}: & \text { Transistor } \\ F_{s}: & \text { Switching frequency } \\ T_{\text {on }}: & \text { ON time } \\ \mathrm{RB}: & \text { Regenerative braking }\end{array}$

\section{Abbreviations}

$V_{1}: \quad$ Input voltage

$V_{o}: \quad$ Output voltage

$V_{c 1}$ : $\quad$ Voltage across capacitor $C_{1}$

$D_{1,2}: \quad$ Diode

$L_{1,2}$ : Inductor

$C_{1,0}$ : Capacitor

$S_{1,2,3,4}$ : Switch

D: $\quad$ Duty ratio

$I_{L 1,2}: \quad$ Inductor current

$I_{c 1, c o}: \quad$ Capacitor current

$T_{1,2,3,4,5,6}$ : Transistor

$F_{s}: \quad$ Switching frequency

RB: $\quad$ Regenerative braking 
$E_{\mathrm{vs}}: \quad$ Electric vehicles

$T_{s}$ : $\quad$ Switching time

PMBLDC: Permanent magnet brushless DC

QGBC: Quadratic gain bidirectional converter

VSI: Voltage source inverter

EMF: Electromotive force

ICE: Internal combustion engine

BDCs: Bidirectional DC to DC converters

CICM: Continuous inductor current mode.

\section{Data Availability}

The data will be available on request to Prof. R. K. Saket (rksaket.eee@iitbhu.ac.in).

\section{Conflicts of Interest}

The authors declare that they have no conflicts of interest.

\section{References}

[1] M. Aamir, S. Mekhilef, and H.-J. Kim, "High-gain zerovoltage switching bidirectional converter with a reduced number of switches," IEEE Transactions on Circuits and Systems II: Express Briefs, vol. 62, no. 8, pp. 816-820, 2015.

[2] H. Ardi, A. Ajami, F. Kardan, and S. N. Avilagh, "Analysis and implementation of a nonisolated bidirectional DC-DC converter with high voltage gain," IEEE Transactions on Industrial Electronics, vol. 63, no. 8, pp. 4878-4888, 2016.

[3] U. R. Prasanna, A. K. Singh, and K. Rajashekara, "Novel bidirectional single-phase single-stage isolated AC-DC converter with PFC for charging of electric vehicles," IEEE Transactions on Transportation Electrification, vol. 3, no. 3, pp. 536-544, 2017.

[4] Y.-E. Wu and I.-C. Chen, "Novel integrated three-port bidirectional DC/DC converter for energy storage system," IEEE Access, vol. 7, pp. 104601-104612, 2019.

[5] Y.-E. Wu and Y.-T. Ke, "A novel bidirectional isolated DCDC converter with high voltage gain and wide input voltage," IEEE Transactions on Power Electronics, vol. 36, no. 7, pp. 7973-7985, 2021.

[6] E. Babaei, Z. Saadatizadeh, and V. Ranjbarizad, "A new nonisolated bidirectional DC-DC converter with ripple-free input current at low-voltage side and high conversion ratio," International Transactions on Electrical Energy Systems, vol. 28, no. 2, Article ID e2494, 2018.

[7] V. V. S. K. Bhajana, P. Drabek, and P. K. Aylapogu, "Design and implementation of a zero voltage transition bidirectional DC-DC converter for DC traction vehicles," International Transactions on Electrical Energy Systems, vol. 29, no. 5, pp. 1-14, 2019.

[8] S.-W. Lee and H.-L. Do, "Quadratic boost DC-DC converter with high voltage gain and reduced voltage stresses," IEEE Transactions on Power Electronics, vol. 34, no. 3, pp. 23972404, 2019.

[9] E. Babaei and O. Abbasi, "A new topology for bidirectional multi-input multi-output buck direct current-direct current converter," International Transactions on Electrical Energy Systems, vol. 27, no. 2, pp. 1-15, 2017.

[10] K. Suresh, C. Bharatiraja, N. Chellammal et al., "A multifunctional non-isolated dual input-dual output converter for electric vehicle applications," IEEE Access, vol. 9, pp. 64445-64460, 2021.
[11] H. Bahrami, S. Farhangi, H. Iman-Eini, and E. Adib, “A new interleaved coupled-inductor nonisolated soft-switching bidirectional DC-DC converter with high voltage gain ratio," IEEE Transactions on Industrial Electronics, vol. 65, no. 7, pp. 5529-5538, 2018.

[12] R. Afzal, Y. Tang, H. Tong, and Y. Guo, "A high step-up integrated coupled inductor-capacitor DC-DC converter," IEEE Access, vol. 9, pp. 11080-11090, 2021.

[13] B. Moon, H. Y. Jung, S. H. Kim, and S.-H. Lee, "A modified topology of two-switch buck-boost converter," IEEE Access, vol. 5, pp. 17772-17780, 2017.

[14] Y. Raj Kafle, M. J. Hossain, and M. Kashif, "Quasi-Z-sourcebased bidirectional DC-DC converters for renewable energy applications," International Transactions on Electrical Energy Systems, vol. 31, no. 4, Article ID e12823, 2021.

[15] P. Padmavathi and S. Natarajan, "Single switch quasi $Z$-source based high voltage gain DC-DC converter," International Transactions on Electrical Energy Systems, vol. 30, no. 7, Article ID e12399, 2020.

[16] A. Priyadarshi, P. K. Kar, and S. B. Karanki, "A wide load range ZVS high voltage gain hybrid DC-DC boost converter based on diode-capacitor voltage multiplier circuit," International Transactions on Electrical Energy Systems, vol. 30, no. 1, pp. 1-18, 2020.

[17] C.-L. Shen, H. Liou, T.-C. Liang, and H.-Z. Gong, "An isolated bidirectional interleaved converter with minimum active switches and high conversion ratio," IEEE Transactions on Industrial Electronics, vol. 65, no. 3, pp. 2313-2321, 2018.

[18] Y. Zhang, W. Zhang, F. Gao, S. Gao, and D. J. Rogers, “A switched-capacitor interleaved bidirectional converter with wide voltage-gain range for super capacitors in EVs," IEEE Transactions on Power Electronics, vol. 35, no. 2, pp. 15361547, 2020.

[19] Y. Shen, H. Wang, A. Al-Durra, Z. Qin, and F. Blaabjerg, “A bidirectional resonant DC-DC converter suitable for wide voltage gain range," IEEE Transactions on Power Electronics, vol. 33, no. 4, pp. 2957-2975, 2018.

[20] Y. Zhang, D. Zhang, J. Li, and H. Zhu, "Bidirectional LCLL resonant converter with wide output voltage range," IEEE Transactions on Power Electronics, vol. 35, no. 11, pp. 11813-11826, 2020.

[21] V. F. Pires, D. Foito, and A. Cordeiro, "A DC-DC converter with quadratic gain and bidirectional capability for batteries/ supercapacitors," IEEE Transactions on Industry Applications, vol. 54, no. 1, pp. 274-285, 2018.

[22] S. V. K. Naresh and S. Peddapati, "New family of transformerless quadratic buck-boost converters with wide conversion ratio," International Transactions on Electrical Energy Systems, vol. 31, no. 11, pp. 1-21, 2021.

[23] A. R. N. Akhormeh, K. Abbaszadeh, M. Moradzadeh, and A. Shahirinia, "High-gain bidirectional quadratic DC-DC converter based on coupled inductor with current ripple reduction capability," IEEE Transactions on Industrial Electronics, vol. 68, no. 9, pp. 7826-7837, 2021.

[24] X. Xiaohong Nian, F. Fei Peng, and H. Hang Zhang, "Regenerative braking system of electric vehicle driven by brushless DC motor," IEEE Transactions on Industrial Electronics, vol. 61, no. 10, pp. 5798-5808, 2014.

[25] F. Naseri, E. Farjah, and T. Ghanbari, "An efficient regenerative braking system based on battery/supercapacitor for electric, hybrid, and plug-in hybrid electric vehicles with BLDC motor," IEEE Transactions on Vehicular Technology, vol. 66, no. 5, pp. 3724-3738, 2017. 
[26] X. Zhang, Y. Wang, G. Liu, and X. Yuan, "Robust regenerative charging control based on T-S fuzzy sliding-mode approach for advanced electric vehicle," IEEE Transactions on Transportation Electrification, vol. 2, no. 1, pp. 52-65, 2016.

[27] M. Kumar, K. Kumar, and K. Chaudhary, "Modified nonisolated bidirectional DC-DC converter for regenerative braking for electric vehicle applications," in Proceedings of the Symposium on Power Electronic and Renewable Energy Systems Control Singapore, Lecture Notes in Electrical Engineering, S. Mohapatro and J. Kimball, Eds., pp. 77-88, Singapore, July 2021. 